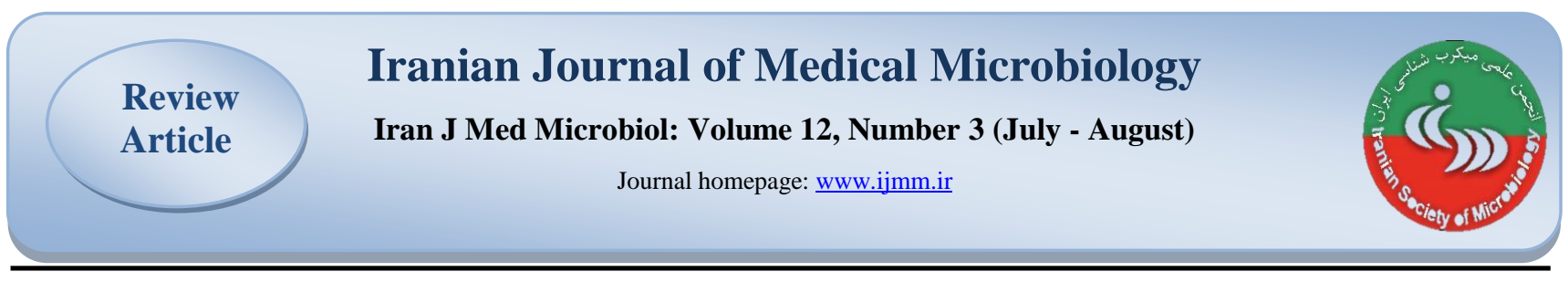

\title{
Medical Function of Bacterial Extracellular Vesicles
}

\author{
Maryam Ebrahimi Vargoorani ${ }^{1,2}$, Mohammad Hossein Modarressi ${ }^{3}$, Mojgan Sheikhpour ${ }^{4,5}$, Seyed Davar Siadat $^{4,5}$ \\ 1. Department of Biology, Science and Research Branch, Islamic Azad University, Tehran, Iran \\ 2. Department of Microbiology, College of Basic Sciences, Tehran North Branch, Islamic Azad University, Tehran, Iran \\ 3. Department of Medical Genetics, Tehran University of Medical Sciences, Tehran, Iran \\ 4. Department of Mycobacteriology and Pulmonary Research, Pasteur Institute of Iran, Tehran, Iran \\ 5. Microbiology Research Center, Pasteur Institute of Iran, Tehran, Iran
}

\section{Article Information}

\section{Article history:}

Received: 2017/11/13

Accepted: 2018/07/15

Available online: 2018/10/11

\section{Article Subject:}

Clinical Microbiology

\section{IJMM 2018; 12(3): 140-159}

Corresponding author:

\section{Seyed Davar Siadat}

Department of

Mycobacteriology and

Pulmonary Research, Pasteur Institute of Iran, Tehran, Iran Tel: 09121442137

Email:d.siadat@gmail.com

Use your device to scan and read the article online

\section{Abstract}

Extracellular vesicles are nanoscale particles which were identified about fifty years ago. The studies have shown that all of the gram-negative bacteria secrete extracellular vesicles during their normal growth. Today, the production of membrane vesicles has been reported by gram-positive bacteria, parasites, fungi, and mycobacteria. Since these nanoscale particles carry many of the bacterial components such as DNA, RNA, protein, endotoxin, and virulence molecules, they play a very important role in interacting with the environment and other bacteria. For this reason, many of these vesicles are considered as the transmission of pathogens, antigenic protein compounds, and the development of non-cellular vaccines, as well as drug delivery agents. The studies, have been carried in this field so far, have been focused on the pathogenic and physiological roles of these nanostructures in cross-species relationships. The focus of this article is on the role of extracellular bacterial vesicles and pathological and physiological functions which contribute to the interactions between bacteria and bacteriumhost. Since these nanostructures play significant role in pathogenesis, gene transduction, regulation of gene expression, immune response regulation, and cellular signaling, further studies are needed on the medical application of these nanostructures as a new generation of vaccines, adjuvants, drug delivery agents.

Keywords: Extracellular vesicles; Adjuvants; Vaccine; Bacterium; Medical application

How to cite this article:

\section{Ebrahimi Vargoorani M, Modarressi M H, Sheikhpour M, Siadat S D. Medical Function of}

Bacterial Extracellular Vesicles. Iran J Med Microbiol. 2018; 12 (3) :140-159 


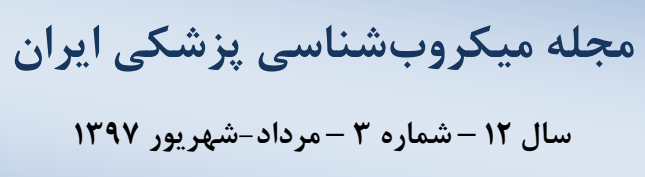

Journal homepage: $\underline{w w w . i j m m . i r}$
مقاله

مرورى

\title{
عملكرد و كاربردهاى بِنشى وزيكولهاى خارجسلولى باكترىها
}

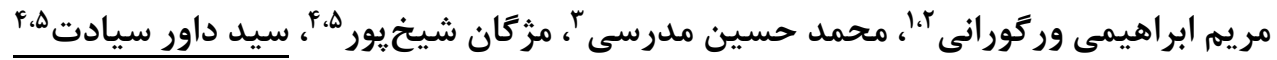

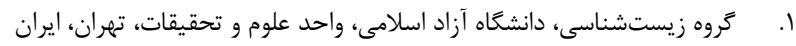

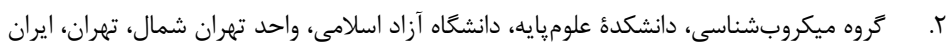

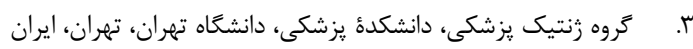

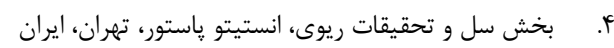

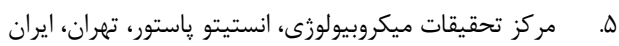

\section{جـكيله}

وزيكولهاى خارجسلولى، نانوساختارهاى سلولى هستند كه در حدود •ه سال بيش شناسايى شدند. مطالعات نشان داده است

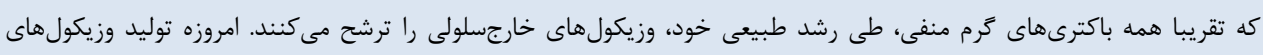

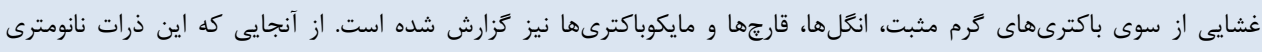

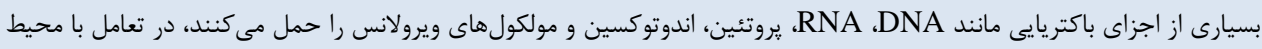

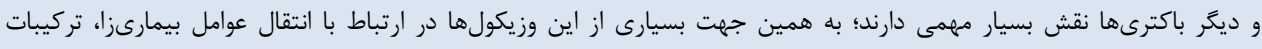

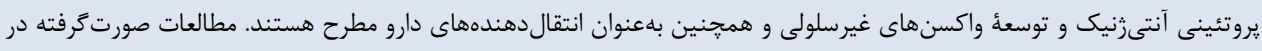

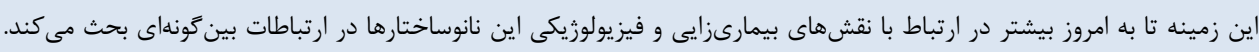

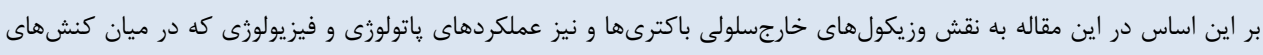

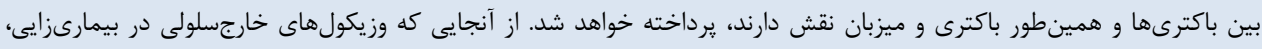

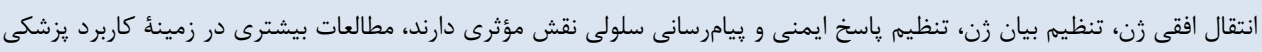

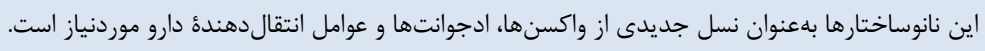

$$
\text { كلمات كليدى: وزيكول هاى خارجسلولى، ادجوانت، واكسن، باكترى، كاربرد يزشكى }
$$

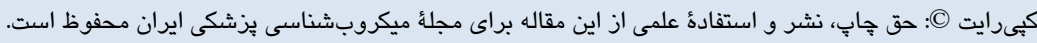

اطلاعات مقاله

\begin{tabular}{|c|}
\hline تاريخحُهُ مقاله \\
\hline 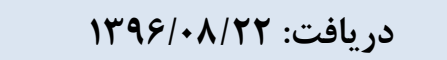 \\
\hline يذيرش:F/FF/FqV|F \\
\hline انتشار آنلاين: \\
\hline موضوع: \\
\hline ميكروب شناسى بالينى \\
\hline IJMM1397;12(3): 140-159 \\
\hline نويسندة مسئول: \\
\hline سيد داور سيادت \\
\hline بخش سل و تحقيقات ريوى، انستيتو \\
\hline 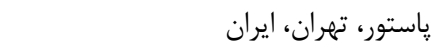 \\
\hline تلفن: 9ITIFFYITV. \\
\hline يست الكترونيك: \\
\hline d.siadat@gmail.com \\
\hline
\end{tabular}

مقلم هـ

منفىها و اكتوزوم و اتزوزوم درباره سلولهاى يستانداران است

وزيكولهاى خارجسلولى باكترىهاى گرم منفى نخستين بار در سال •9919 در مطالعات ساختارهاى باكتريايى با استفاده از

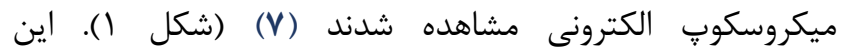

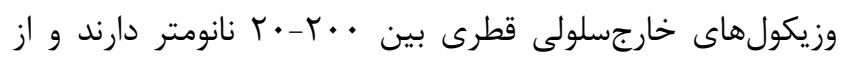
بسيارى از باكترىهاى گرم منفى ترشح مىشوند (Y-1).

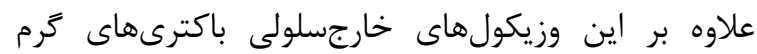
منفى در شرايط محيطى مختلف كشف شدند؛ ازجمله در شرايط بـ

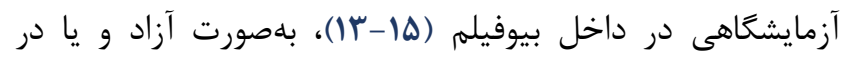

وزيكولهاى خارجسلولى بهعنوان اجزاى تكاملى حفاظت شده بين سلولى هستند. همدٔ انواع قلمروهاى حيات روى زمين كه به

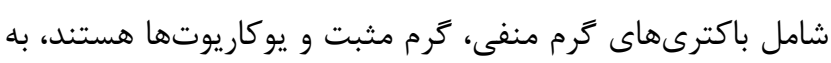
شكل فعال وزيكولهايى با اندازه نانومترى ترشح مى كنند (r)، (). اين ساختارها گرد، دولايه و حاوى مواد فعال بيولوزيكى ازجمله يروتئين، ليييد، اسيدنوكلئيك و متابوليتها هستند (ه- (ب). اصطلاحات متنوعى براى وزيكولهاى خارجسلولى در نظر گرفته مىشود كه شامل وزيكولهاى غشايى در ارتباط با باكترىهاى

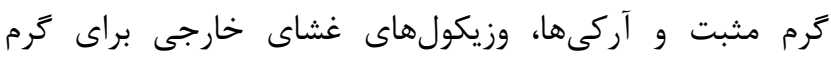




\section{Gram-positive MV}

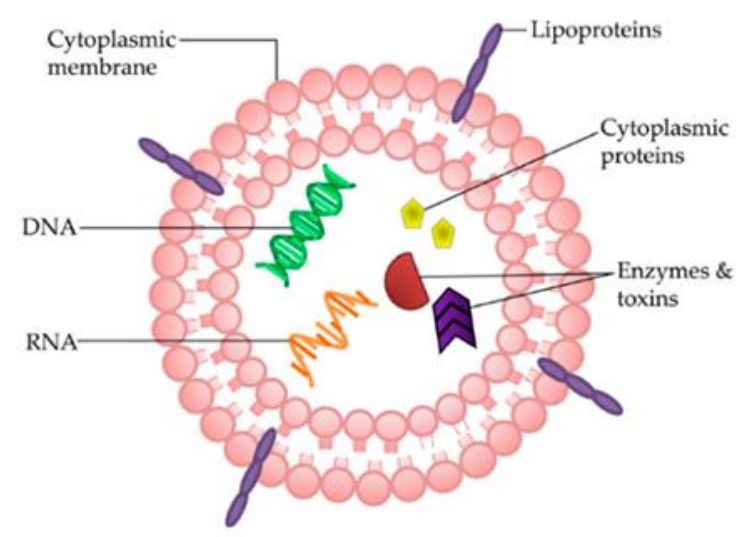

شكل ז. ساختار و اجزاى تشكيل دهندة وزيكولهاى خارجسلولى

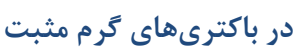

\section{نقش وزيكول هاى خارجسلولى در باكترىها}

وزيكولهاى خارجسلولى بهعنوان سيستم ترشحى براى

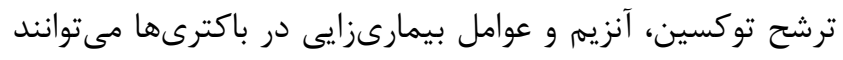

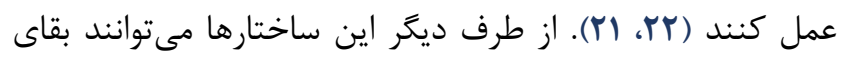

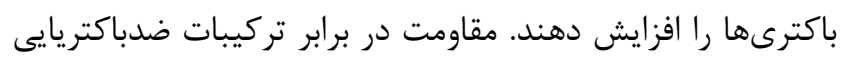

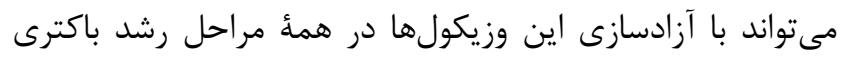

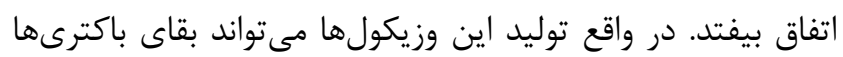

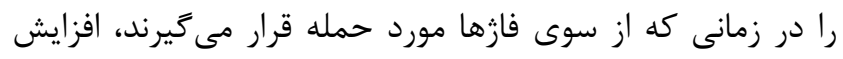

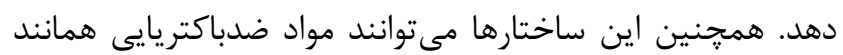

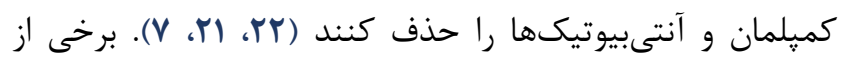

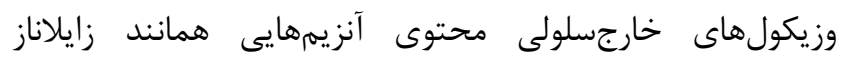

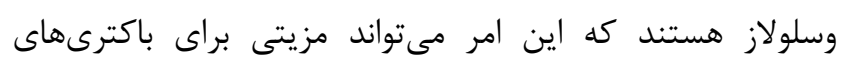

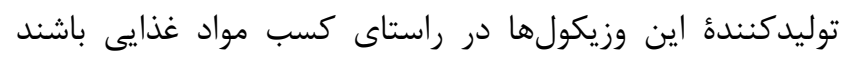

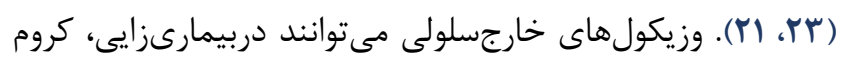

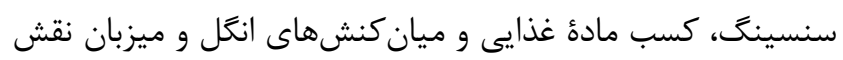

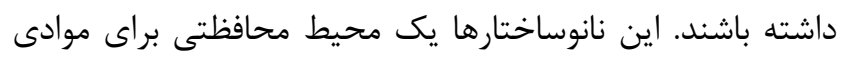

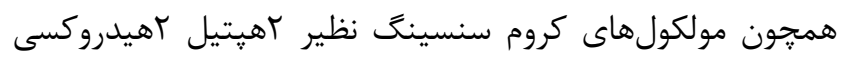
باكينولون (PQS يا سيكنال كينولون سودوموناس) نيز هستند.

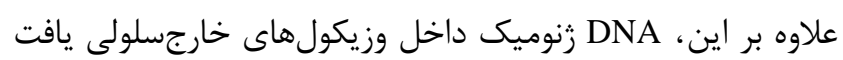

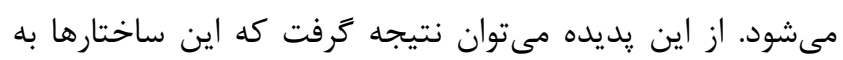

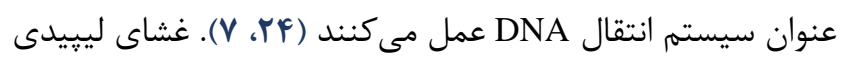

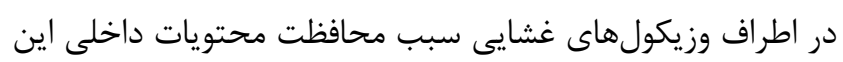

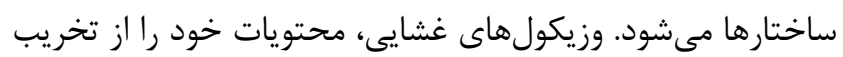

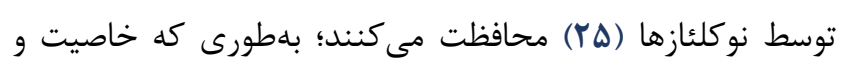

محيطهاى طبيعى همانند فاضلاب، خاك، مايعات بيولوزيكى و

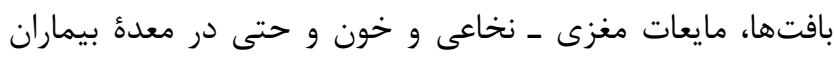
آلوده به Helicobacter pylori

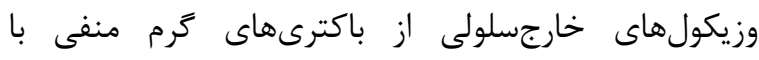

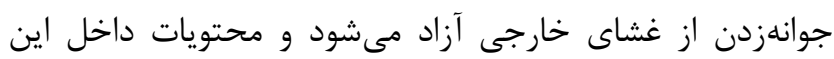

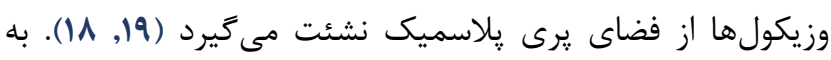

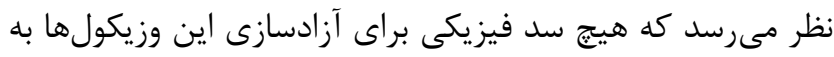

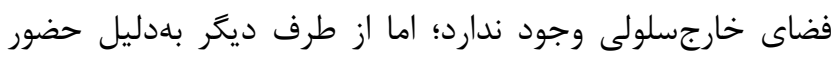

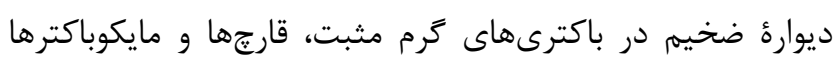

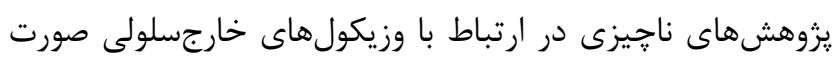

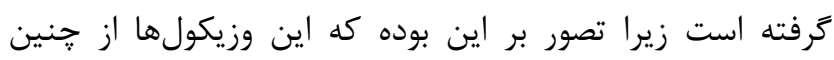
سدهاى بزرى نمى توانند عبور كنيند.

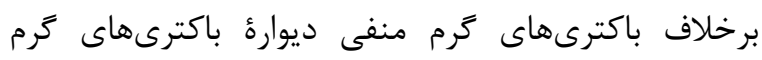

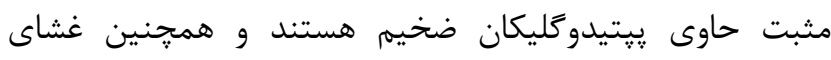

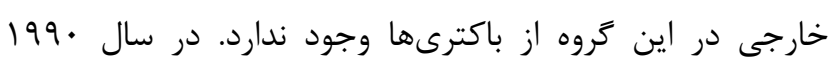

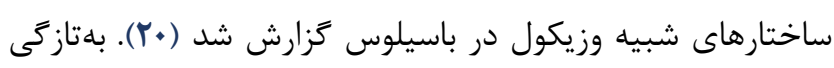

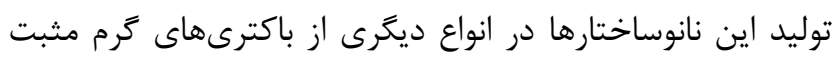

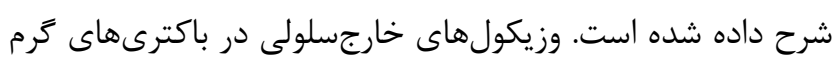

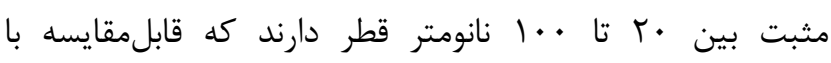

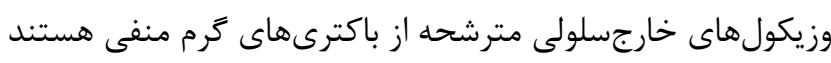

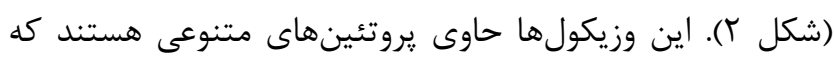
براى بقاو ويرولانس باكترى اهميت دارند (1).

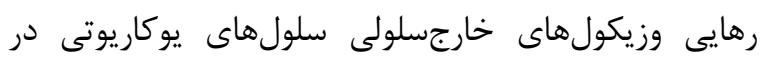

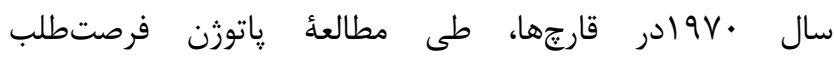
شا Cryptococcus neoformans

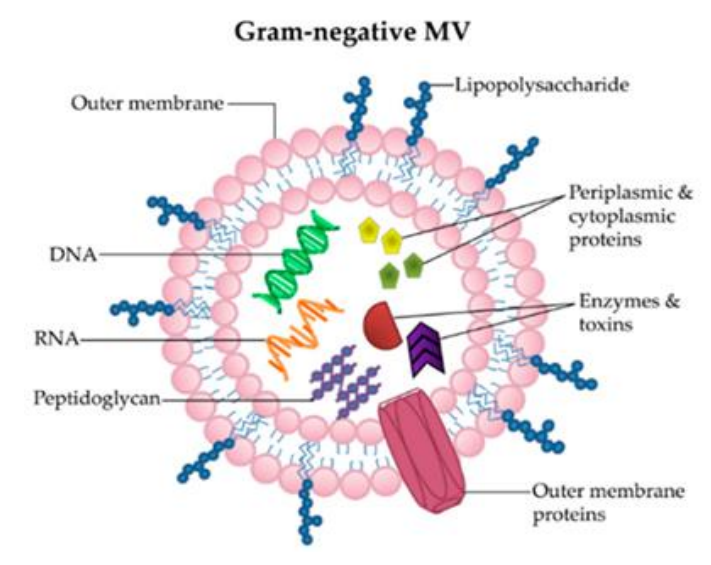

شكل ا. ساختار و اجزاى تشكيلدهندة وزيكول خارجسلولى در

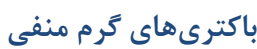


وزيكولهاى خارجسلولى باكترىهاى كرم منفى مى توانند

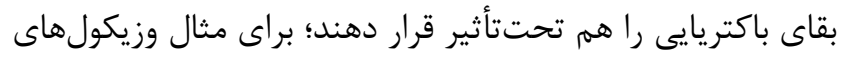

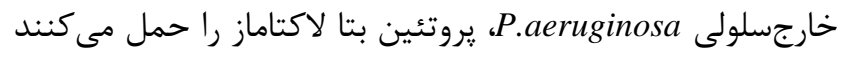

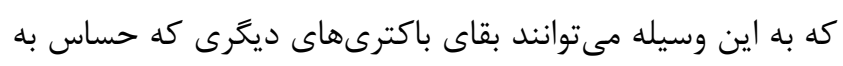

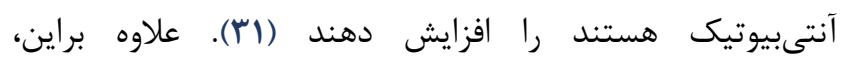

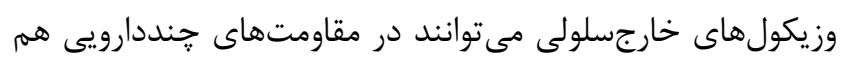

نقش داشته باشند (ب).

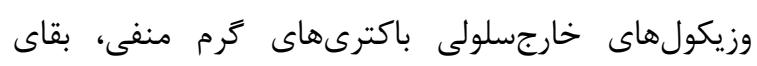

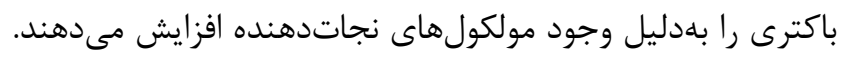

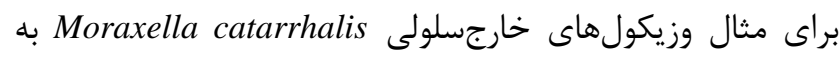
بقاى Haemophilus influenzae در مقاى مقابل حملات ميلات ميانجى

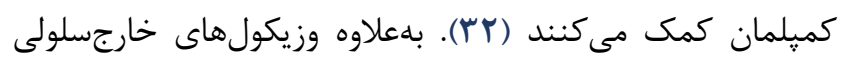

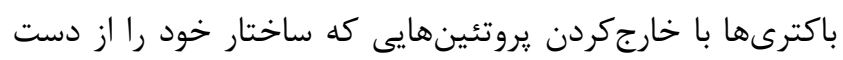

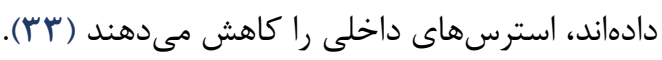
نقش وزيكولهاى خارجسلولى در ميانكنشهاى باكترى - ميزبان ميانكنش بين وزيكولهاى خارجسلولى باكترىهاى كرم

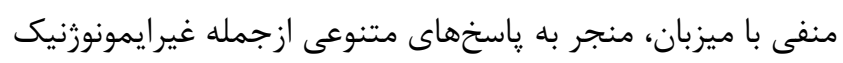

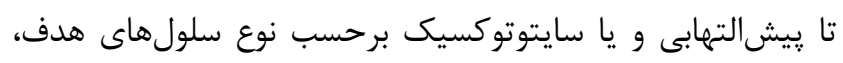

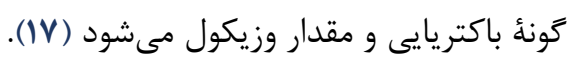

\section{نقش وزيكولهاى خارجسلولى در اختلال ايمنى و} ايجاد بيمارى از آنجايى كه وزيكولهاى خارجسلولى ياسخهاى ايمنى ذاتى

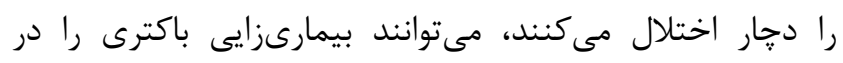

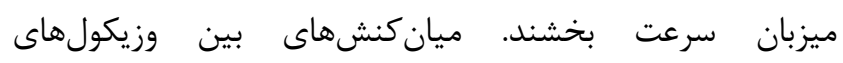

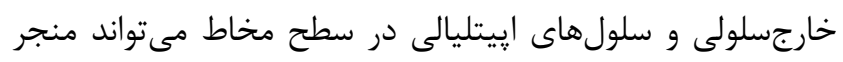

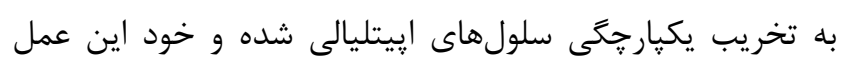

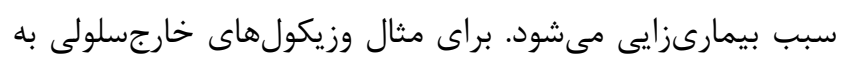

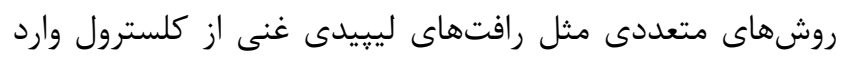

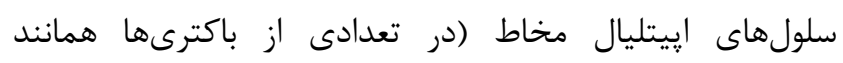

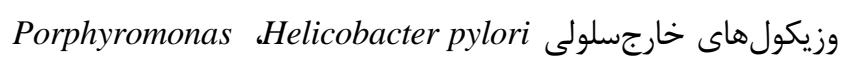
(P. aeruginosa gingivalis

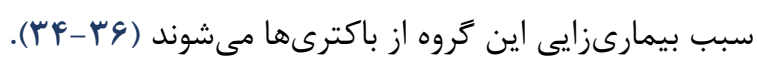

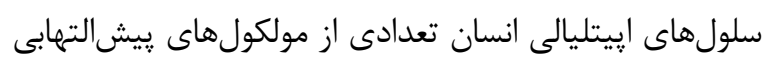

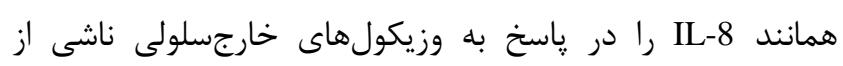

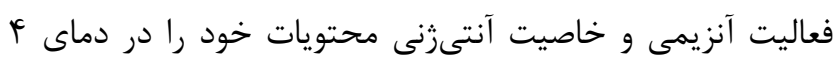

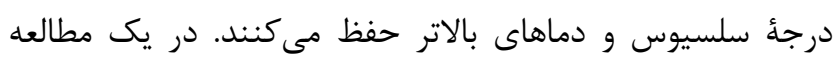

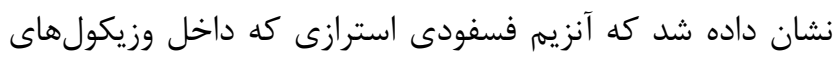

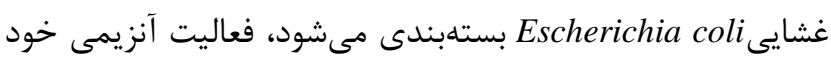

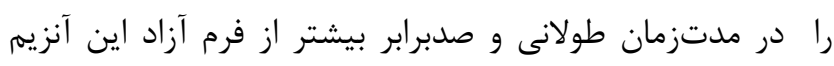

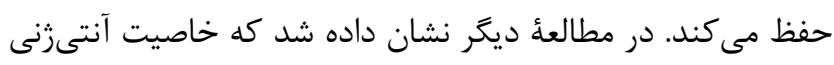

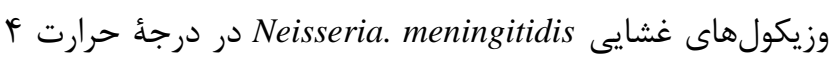

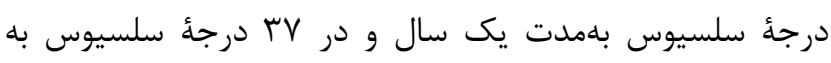

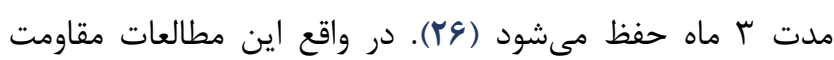

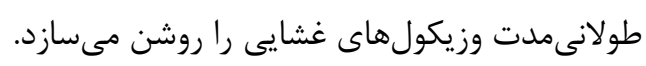

\section{عملكردهاى وزيكول هاى خارجسلولى باكترى هاى كرم}

منفى

وزيكولهاى خارجسلولى باكترىهاى كَرم منفى عملكردهاى

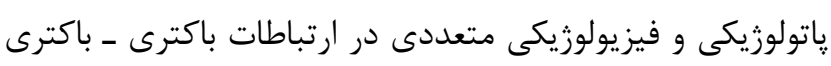

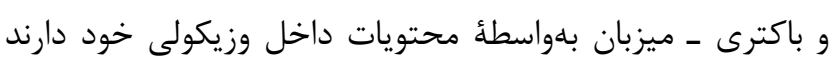

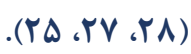

نقش وزيكولهاى خارجسلولى در ارتباطات باكترى -

باكترى

باكترىها از وزيكولهاى خارجسلولى خود در راستاى ارتباط

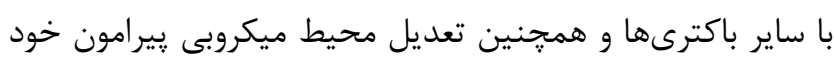

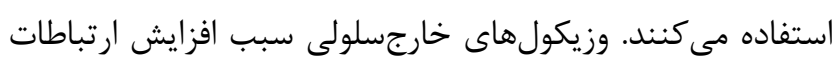

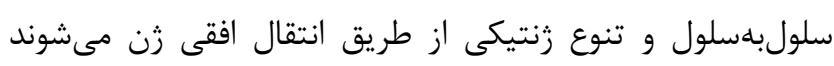

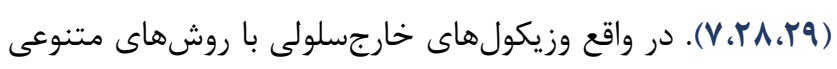

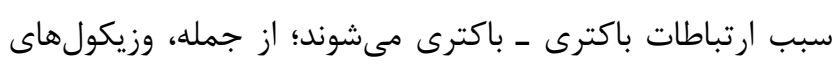
خارجسلولى Pseudomonas aeruginosa نقش مهمى داكتي در انتقال

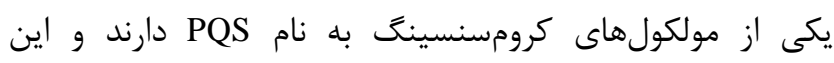
مولكولهاى PQS داخل وزيكولى مىتوانيند با باكترىها باصصورت مستقيم از طريق LPS ارتباط برقرار كنند (r (T).

وزيكولهاى خارجسلولى باكتريايى مىتوانند در تشكيل

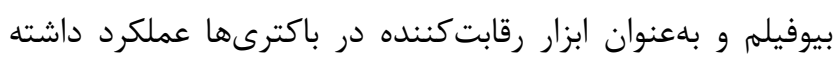

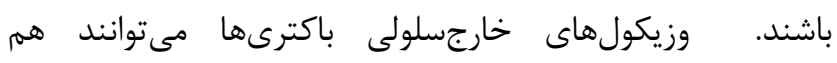

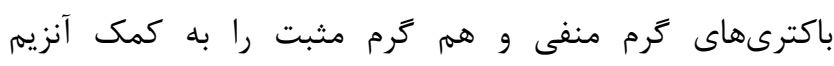

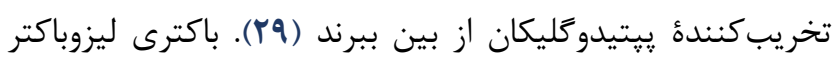

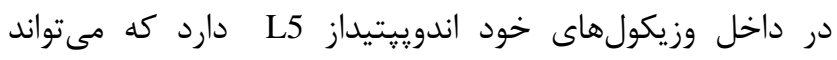
باكترىهاى رقابت كننده را از بين ببرد (•؟). 
تعدادى از الكوهاى مولكولى در ارتباط با ميكرواركانيسم همانند:

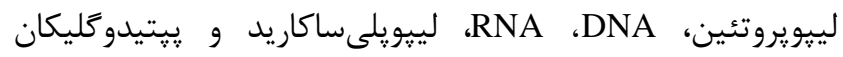

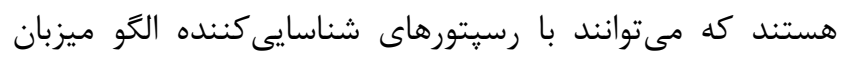

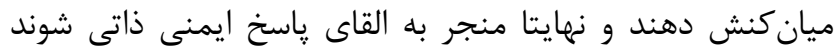
(شكل (). براى مثال وزيكولهاى خارجسلولى توليدشده از سوى P.aeruginosa Neisseria gonorrehoeae iH.pylori سلولهاى إيتليالى ميزبان مىشوند و درنهايت از طريق رسيتور ايمنى سيتويلاسمى NOD1 شناسايى مىشوند كه منجر به ايجاد

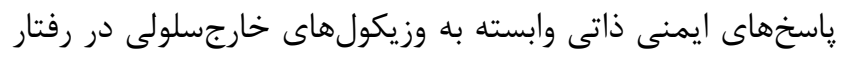
وابسته به NOD1 خواهد شد (צ (؟). بهتازگى نشان داده شده است

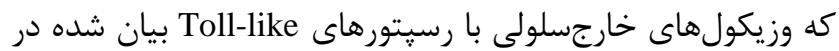

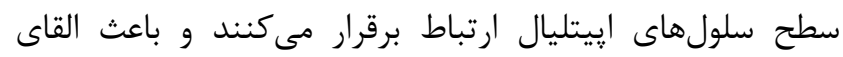

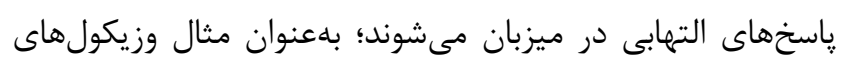

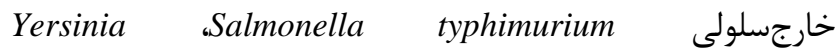
pseudotuberculosis طريق TLR-4 را ميانجى كرى مى كنند (اله). علاوه بر اين، وزيكولهاى خارجسلولى مىتوانند از طريق TLR هاى سلولهاى ايمنى ذاتى سيكنال دهند تا بيمارىزايى و التهاب را تنظيم كنند.

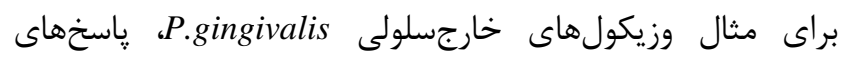
TNF

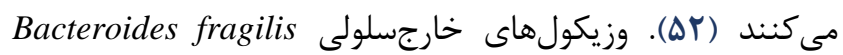

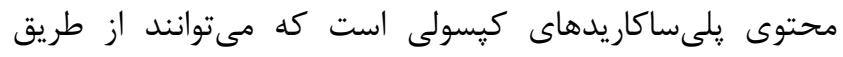

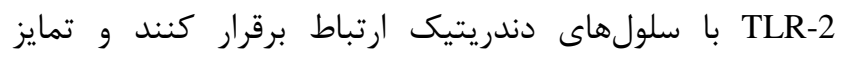
سلولهاى T تنظيمى توليدكننده IL-10 و حفاظت در برابر كوليت ايجادشده را ميانجى كرى كنند (r) الهائ.

نقش وزيكولهاى خارجسلولى در تعديل پِاسخهاى

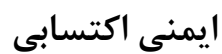

تعديل ياسخهاى ايمنى اكتسابى عليه باكترىهاى بيمارىزا با

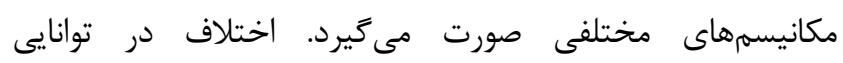
وزيكولهاى خارجسلولى بهمنظور فعال يا سركوبكردن باسختهاي

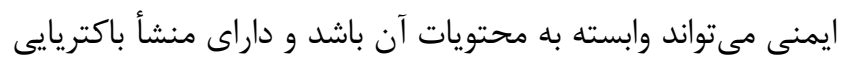

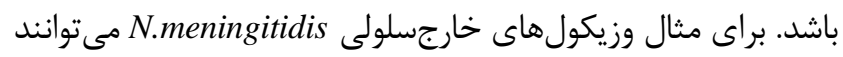
فعالشدن و تكثير T-cell هاى CD4+ را مهار كنند و نوعى سركوب ايمنى را در اطراف جايگاه عفونت ايجاد كنند (AP) و يا اينكه تكثير

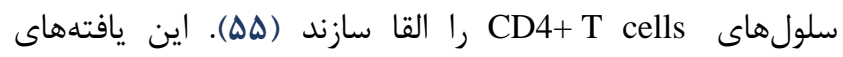

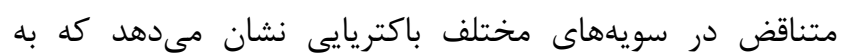

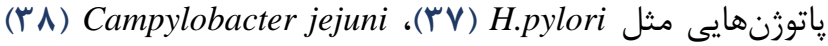

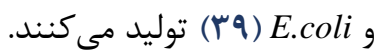

\section{وزيكولهاى خارجسلولى و تعديل سيستم ايمنى}

ميانكنشهايى كه بين وزيكولهاى خارجسلولى و سلولهاى

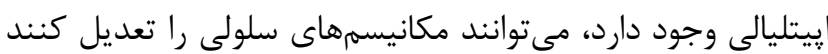

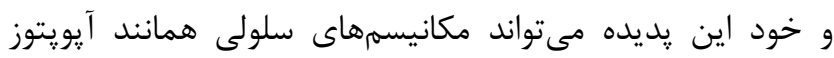

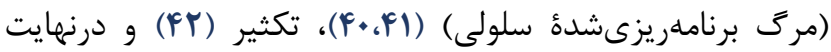
باسخهاى ايمنى را كنترل كند. Cronobacter sakazakii باعندوان

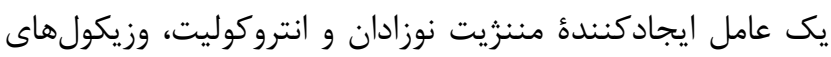

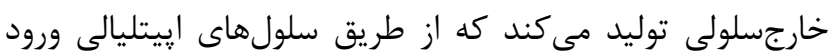

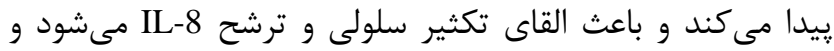

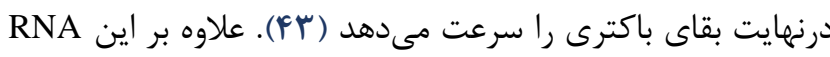

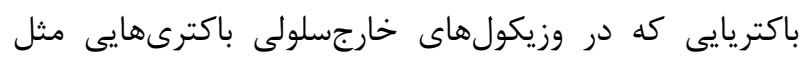

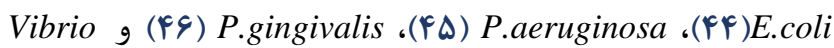
وجود دارد توانايى تحريك سيستم ايمنى را در (FV) cholerae

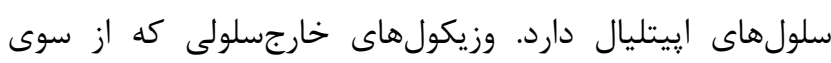

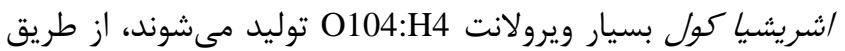

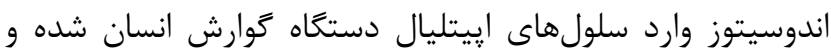

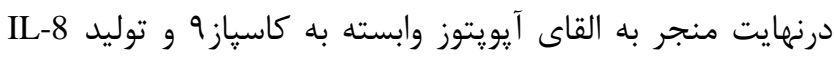

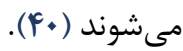

\section{ميان كنش وزيكولهاى خارجسلولى با سيستم ايمنى} ذاتى

با توجه به مطالعات صورتكرفته، معلوم شده است كه وزيكولهاى خارجسلولى مىتوانند نقش مهمى در كشتار وابسته به

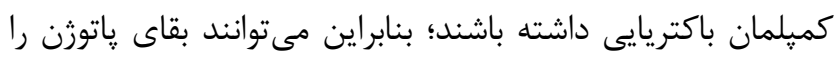
Vر ميزبان تسهيل كنند. وزيكولهاى خارجسلولى V.cholerae محتوى فاكتور ويرولانس ompU هستند كه بقاى اين باكترى را از

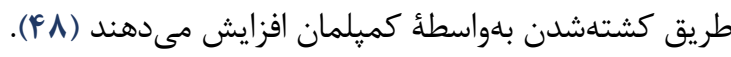
وزيكولهاى خارجسلولى P.gingivalis محتوى آنزيم Peptidyl arginine deiminase

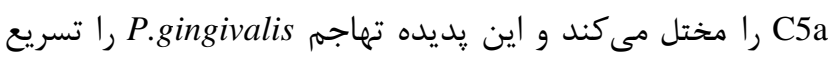

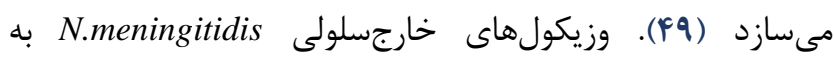
ينتاكسين r متصل مىشود كه از جمله كليكويروتئينهاى فاز التهابى حاد است و در فعالشدن كميلمان نقش دارد (•هان.

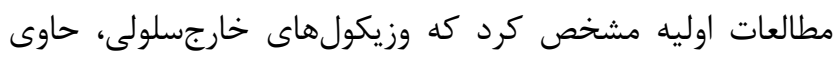


خارجسلولى S.aureus با پيشرفت درماتيت آتوييك گزارش شد

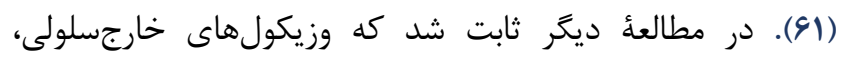

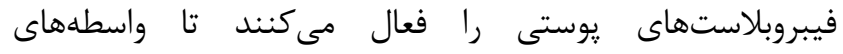

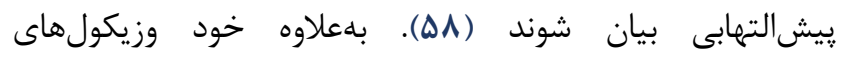
خارجسلولى S.aureus سبب ضخيمشندن إيبدرم و التهابى شبيه درماتيت آتوييك مىشوند (با افزايش نفوذ ائوزينوفيلها و ماست إيدا

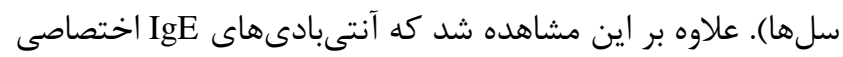

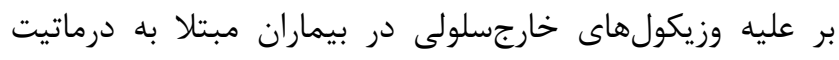

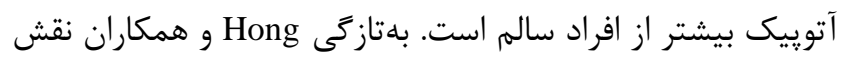

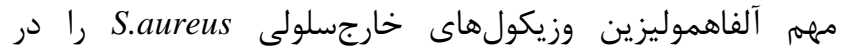

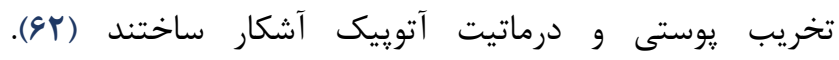

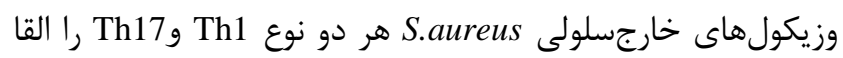
مىكنند و باعث التهاب نوتروفيلى ريه مىشوند و افزايش

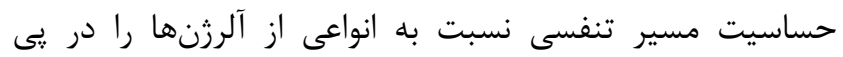

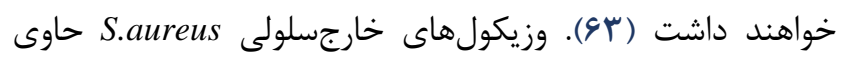

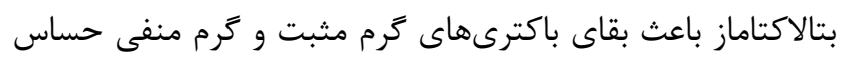

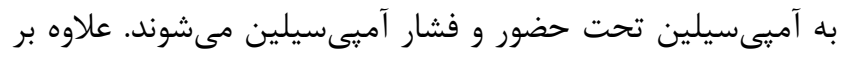
ATTC14458 S.aureus كونههاى آزمايشًاهى ديخر و ايزولههاى كلينيكى S.aureus هم

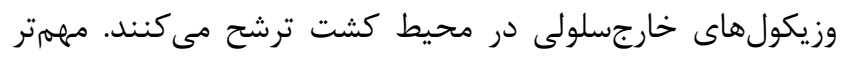

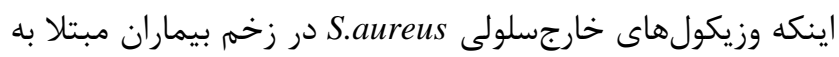

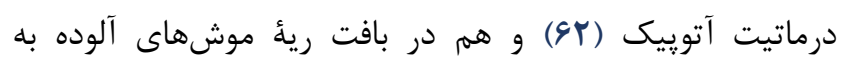
S.aureus شواهد نشان مىدهد كه توليد وزيكولهاى خارجسلولى بهصورت

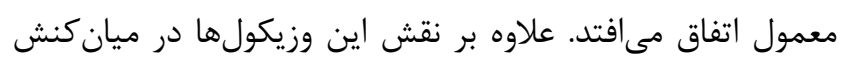
باكترى - ميزبان وزيكولهاى خارجسلولى S.aureus مى توانند فعاليت سايتوتوكسيك بر بسيارى از سلولها داشته بارئه باشند؛ مانند وزيكولهاى خارجسلولى S.aureus كه حاوى آلفاهموليزين هستند

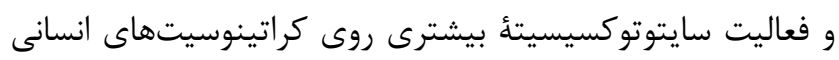
HaCaT

\section{وزيكولهاى خارجسلولى ديگر باكترىهاى ترم مثبت}

B. anthracis

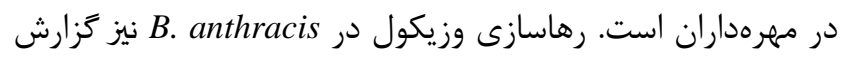

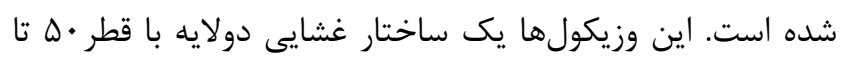

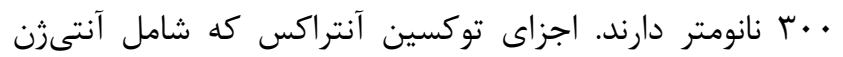

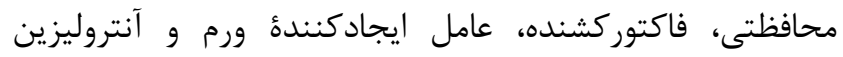

يزوهشهاى بيشترى در اين زمينه نياز است (هد). وزيكولهاى

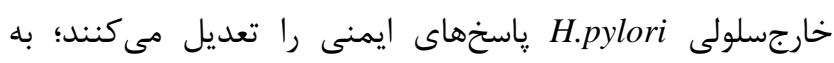
طورى كه تكثير ا مهار و باعث القاى آيويتوز

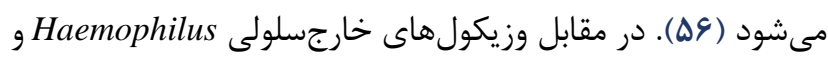
Moraxella

\section{وزيكول هاى خارجسلولى باكترى هاى كرم مثبت}

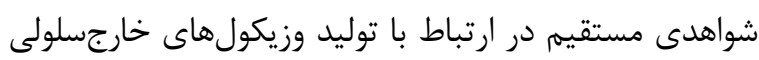

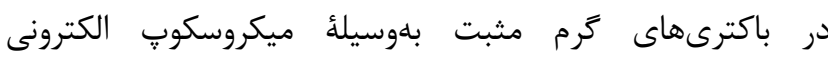

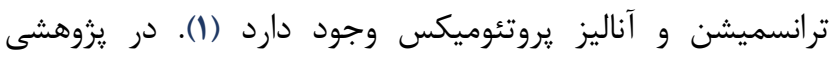
وزيكولهاى خارجسلولى باكترى كرم مثبت

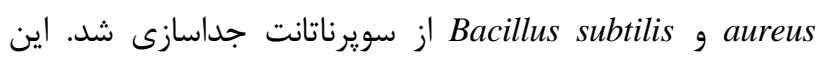
وزيكولهاى جداسازىشده گرد، دولايه و ساختارهاى غشايى بسته

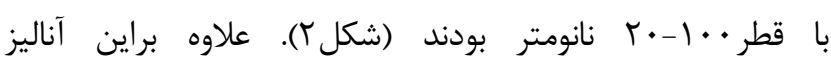

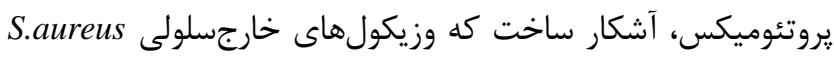

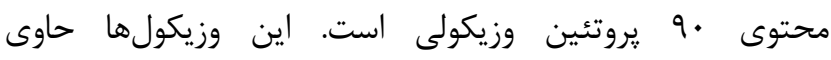
يروتئينهاى ويرولانت خارجسلولى و يا در ارتباط با سطح همانين ائند

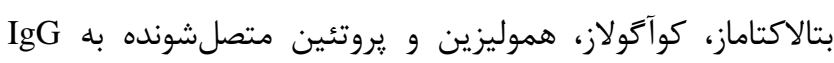

مطالعات بيشتر در ارتباط با گونهاى گرم مثبت، آشكار ساخت

Listeria Streptomyces coelicolorBacillus anthracis Streptococcus .Clostridium perfringens، monocytogenes Lactobacillus plantarum، Streptococcus pneumoniae، mutans و Lactobacillus casei هم وزيكول هاى خارجسلولى توليد مى كنند

.$(1.09 .9 *)$

اين مشاهدات بيان ميى كند كه ترشح وزيكولهاى خارجسلولى يك يروسهٔ كاملا حفاظتشده تكاملى در باكترىهاى كرم مثبت است.

\section{وزيكولهاى خارجسلولى/ستافيلوكوكوس /ورئوس}

بعد از كشف اولئٔ وزيكول هاى خارجسلولى /ستافيلوكوكوس

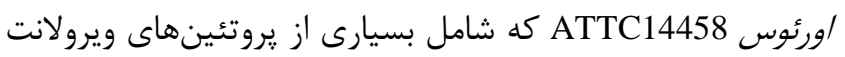

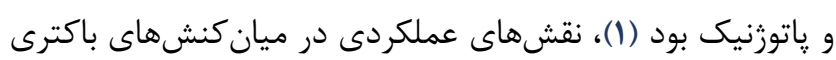

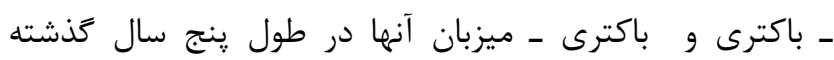

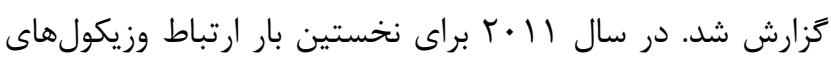


ورود L.monocytogenes به سلولهاى إيتليال ميزبان نياز است؛ در حالى كه ليستريوليزين O باعث ليز واكوئلها مىشود (99). لاكتوباسيلوس يك جنس از باكترىهاى بىهوازى اختيارى

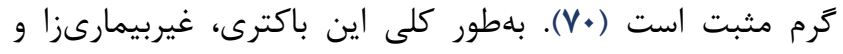
بىخطر شناخته شده و بهطور كسترده در غذاهاى تخميرى مورد

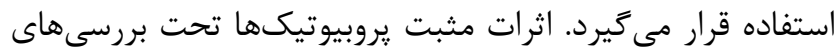

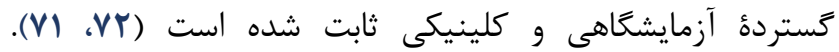

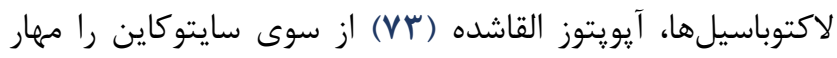

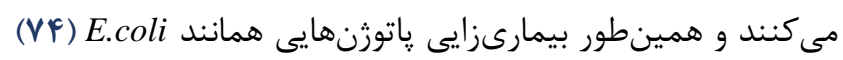

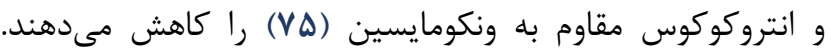
لاكتوباسيلوسها مىتوانند اثرات تعديل كننده روى مكانيسمهاى

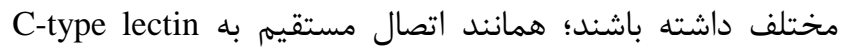
receptors و يا Toll-like receptors در سطح سلول ميزبان كه يكى از مكانيسمهاى تعديل كننده محسوب مىشود (VY)، VY).

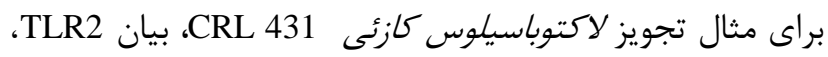

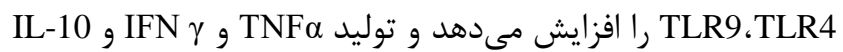
را بهبود مىبخشد (V\&). از طرف ديكر لاكتوباسيلها مواد

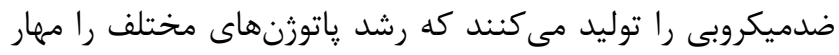

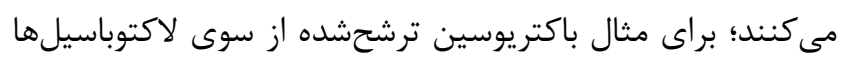

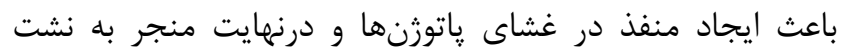
سلول هدف مىشود (VA VQ). امروزه مطالعات ثابت كرده است

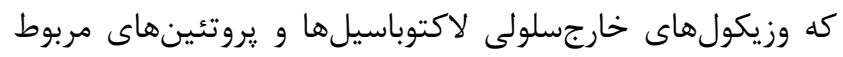
به آنها مىتواند فعاليت سلولهاى ايمنى را التعديل كرده و ״ياسخهاى ايمنى ذاتى و اكتسابى را تحت تأثير قرار دهند (1), •^).

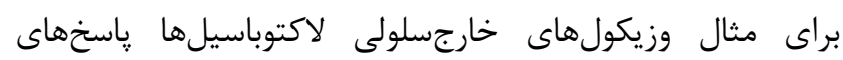
سلولى TLR2/1 و TLR4 را افزايش ميدهند در حارسلولى حالى كه انتقال سيخنال TLR2/6 را مهار مى كنند (r). در مطالعهاى يزوهشكران دريافتند كه وزيكولهاى تئاي

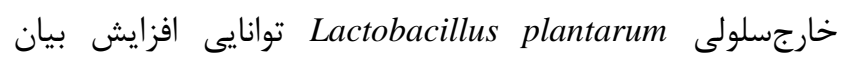
زنهاى دفاعى ميزبان را دارد؛ به طورى كه مىتوان از وزيكولهاى خارجسلولى اين باكترى در درمان Enterococcus faecium مقاوم انسان

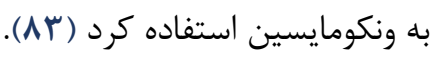

در يزوهش ديكرى ثابت شد كه وزيكولهاى خارجسلولى

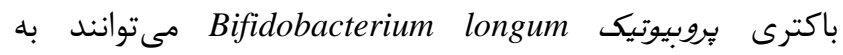

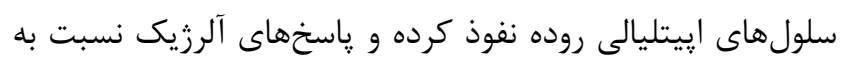

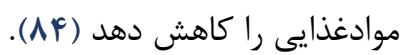

هستند، در وزيكولهاى غشايى B. anthracis شناسايى شدهاند

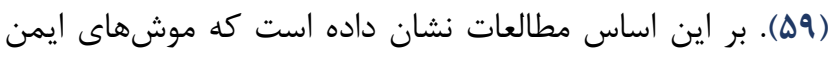

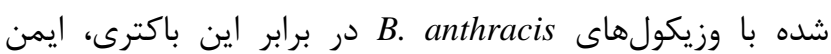

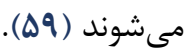

Mycobacterium ulcerans يوست و بافتهاى زير جلدى را دركير مى كند و بهعنوان يكى عامل اتيولوزيك از زخم Buruli است. مايكولاكتون بهعنوان تنها فاكتور

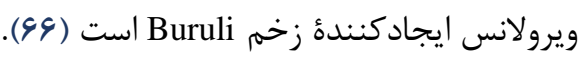
M.ulcerans دهد كه اين ماتريكس حاوى وزيكول و مايكولاكتون است. وزيكولهاى حاصل از M.ulcerans فعاليت سايتوتوكسيك دارد كه به نظر مىرسد بهدليل حضور مايكولاكتون در اين وزيكولها است است

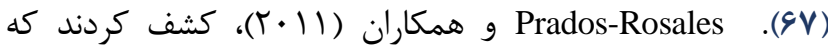

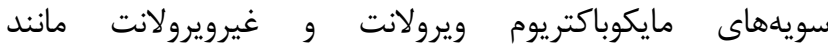
Mycobacterium tuberculosis .Mycobacterium bovis 9 Mycobacterium phlei Mycobacterium Kansasii Mycobacterium avium وزيكولهاى غشايى آزاد مى كنند. آناليز

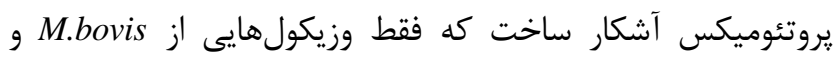
M.tuberculosis

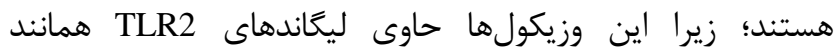

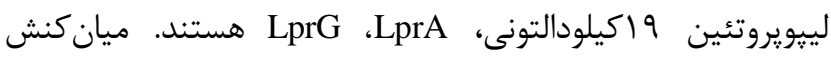
وزيكولهاى غشايى با ماكروفازهاى موش باعث القاى سيتوكاين و

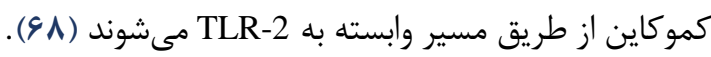
Listeria monocytogenes

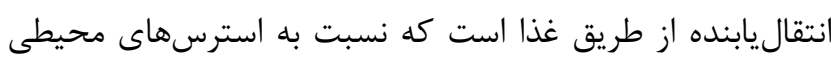

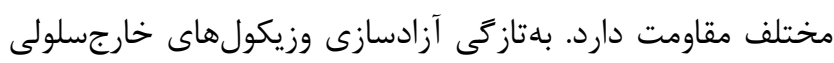

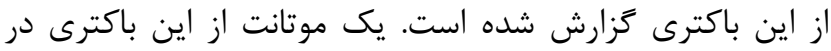

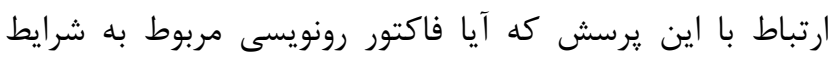

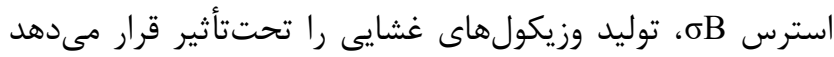
يا خير مورد بررسى قرار كرفت. L. monocytogenes وحشى و

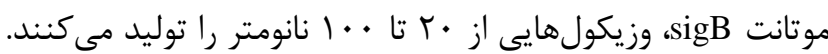

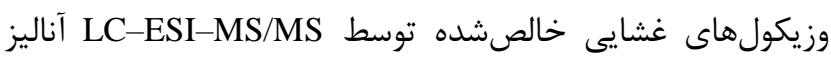

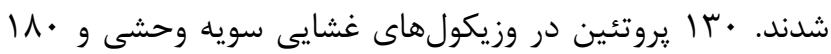

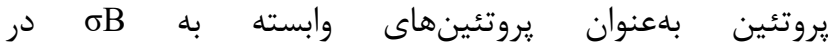
و B تحت شناسايى قرار كرفت. اينترنالين L.monocytogenes

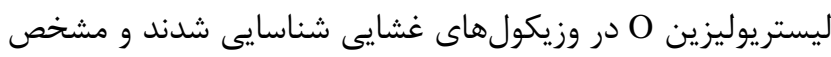
شد كه هم در سويأ وحشى و هم سويؤ موتانت، ايتنرنالين B براى 
وزيكولهاى خارجسلولى بهعنوان نسل جديدى از واكسن و ادجوانت

امروزه بهدليل مقاومتهاى آنتىبيوتيكى گسترده تقاضاى بيشترى در راستاى توليد نسل جديدى از واكسنها وجود دارد. تركيبات توليدشده براساس وزيكولهاى خارجسلولى بلى بلهبب

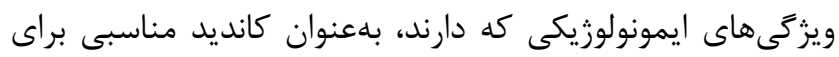
واكسن مطرح هستند.

Raeven

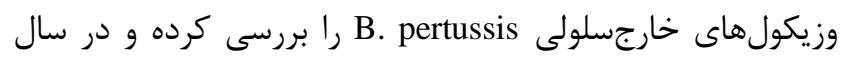

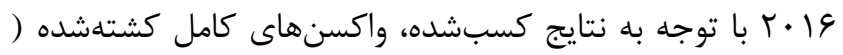
ا ا ا Bordetella pertussis (whole-cell, killed antigen واكسنهايى براساس وزيكولهاى خارجسلولى مقايسه كردند. در هر دو مطالعه ثابت شد كه ياسخ ايمنى مؤثرى ايجاد مى شود (19،

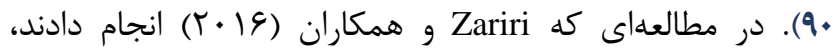

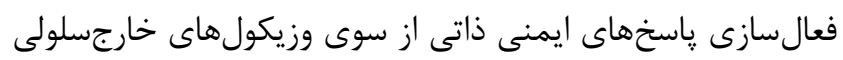
N. meningitidis Choi S.aureus

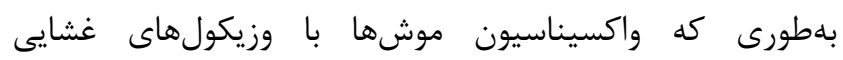
منجر به קِاسخهاى ايمنى سلولى و همورال شد. علاوه

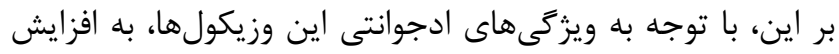

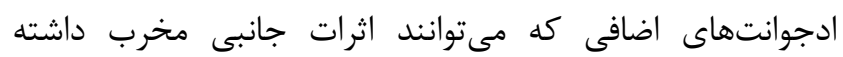

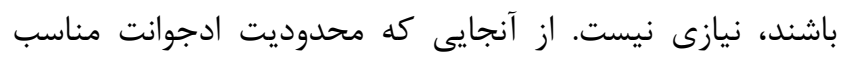

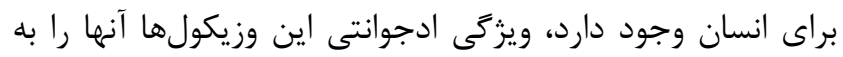

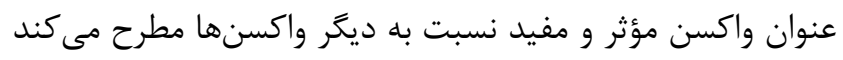

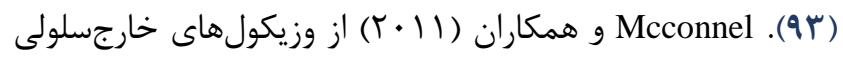
Acinetobacter baumannii

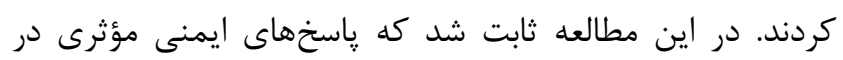

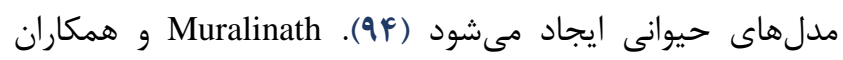

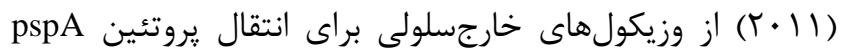
بلمنظور ايمنىزايى عليه Streptococcus pneumoniae استفاده

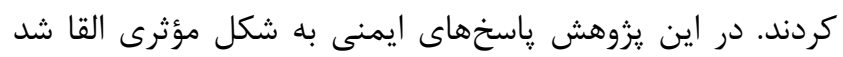

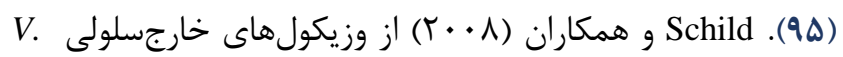
cholerae

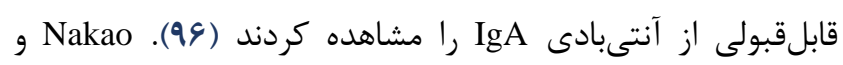

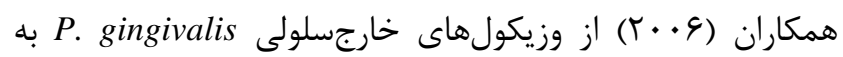
عنوان آنتىثن واكسن در راستاى ايمنىزايى موشهاى

\section{وزيكولهاى خارجسلولى ياتوزنهاى غيرباكتريايى}

امروزه شواهد قطعى در ارتباط با اينكه باكترىهاى كرم

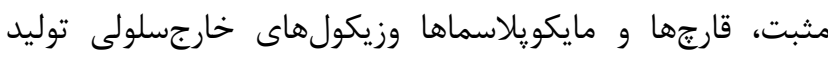
مىكنند وجود دارد اين وزيكولها در دسترس بوده و از نظر

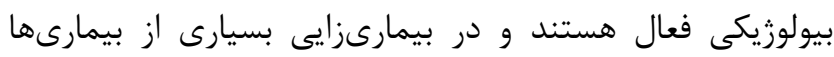
نقش دارند (^ه). پاتورنهاى غيرباكتريايى هم وزيكولهاى خارجسلولى توليد مى كنند كه عامل بيمارىزايى هستند. Trichomonas vaginalis

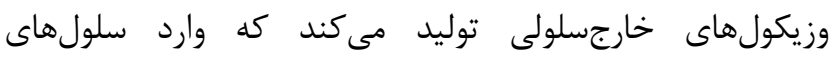
اكتوسرويكال شده، باعث القاى توليد IL-6 و IL-8 مىشوند و

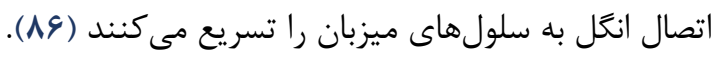
وزيكولهاى خارجسلولى Trypanosoma brucei، يروتئينهاى

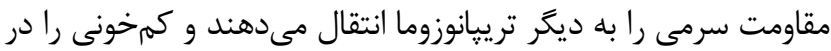

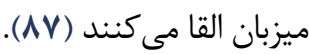
سلولهاى يوكاريوتيك كه بهوسيلة پاتوزنهاى داخل سلولى آلوده مىشوند نيز مىتوانند وزيكولهاى خارجسلولى توليد كنند

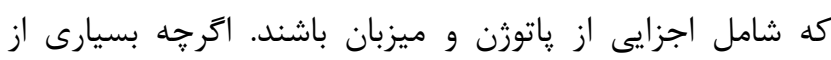

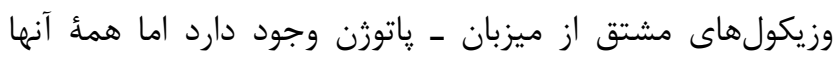

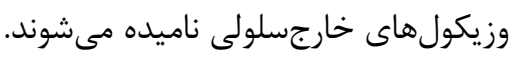

انغل هايى مثل Plasmodium falciparum هم مىتوانند سبب توليد وزيكولهاى خارجسلولى از سلولهاى آلوده ميزبان شوند. وزيكولهاى خارجسلولى P.falciparum حاوى بروتئينهاى إلى تعديل كنندة سيستم ايمنى، يروتئينهاى لازم براى تهاجهم به

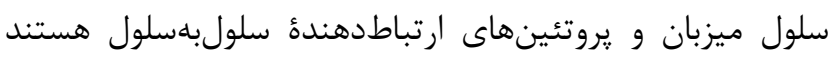

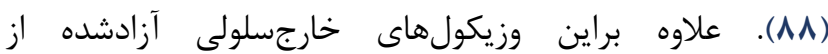
P.falciparum

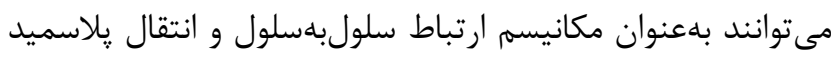

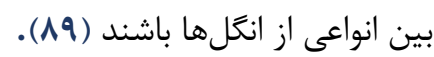

\section{كاربردهاى مهمم يزشكى وزيكول هاى خارجسلولى}

وزيكولهاى خارجسلولى كاربردهاى يزشكى متنوعى براى

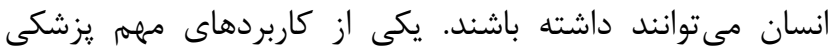

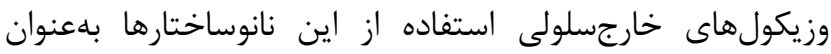

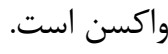


بلهنوان يك زَينه مناسب براى درمان سرطان مطرح مى كند

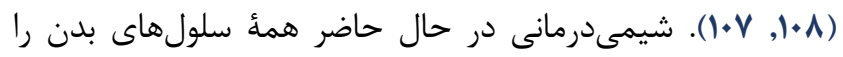

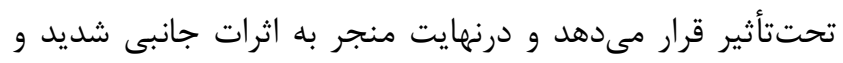

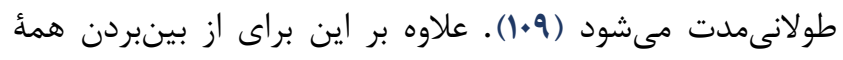
سلولهاى سرطانى يك دوز بالايى از شيمىدرمانى لازم است.

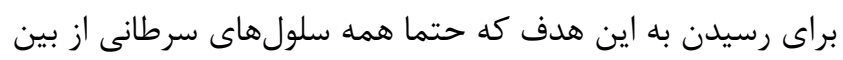

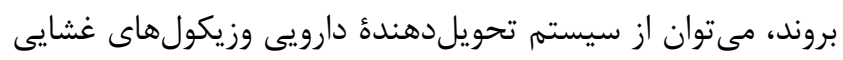

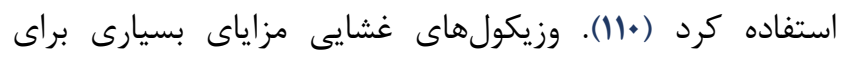

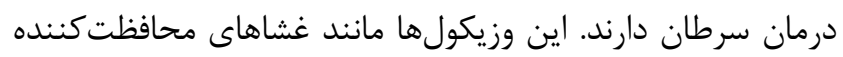

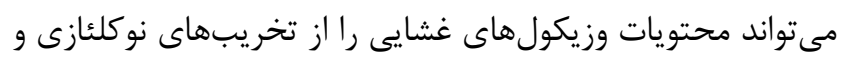

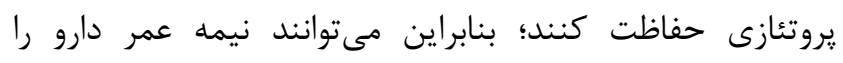

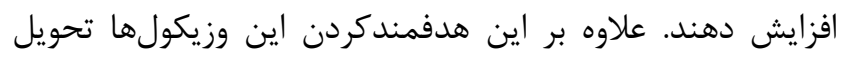

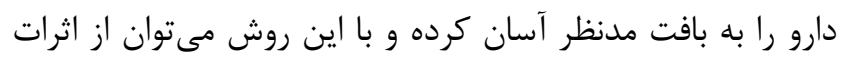

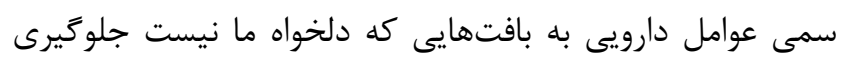

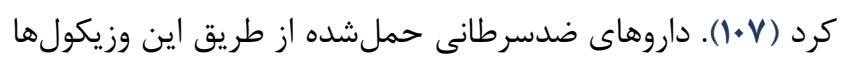

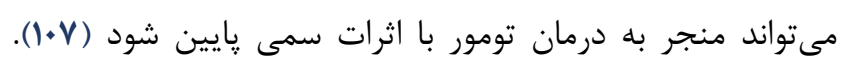
Gujrati

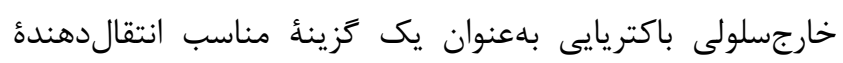

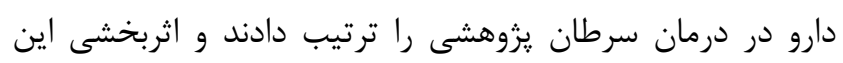

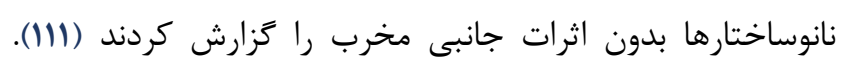

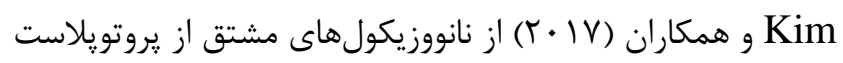

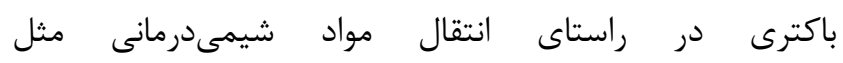
doxorubicine

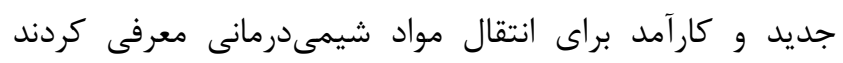

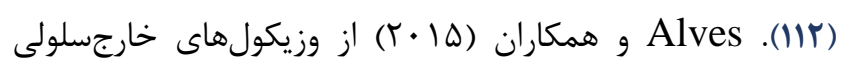

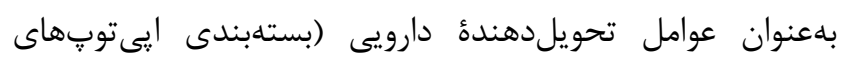

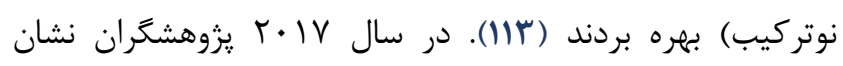

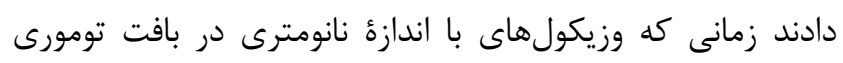

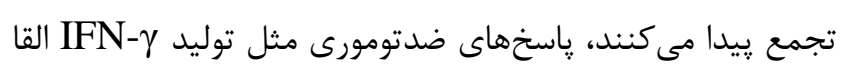

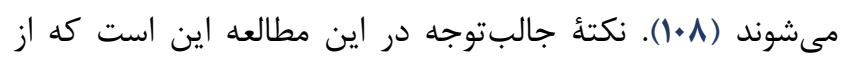

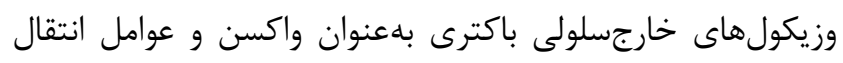

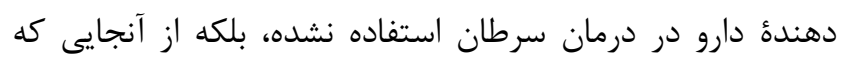

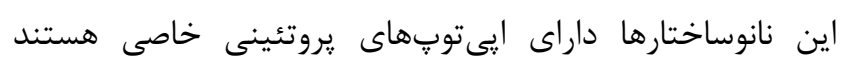

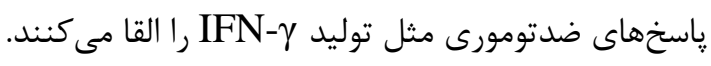

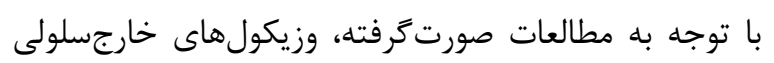
بهدليل داشتن غشاى محافظت كننده و اندازء نانومترى و و قابليت

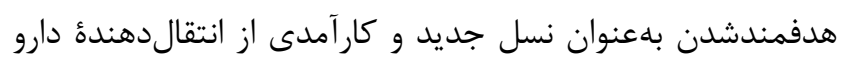

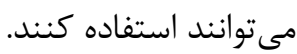

بهره بردند؛ بلهورى كه در موشهاى ايمنشده با اين واكسن

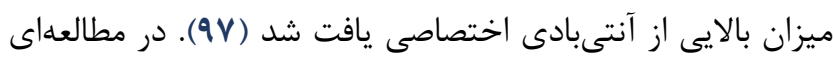

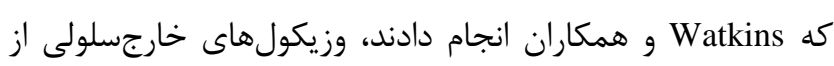
E. coli

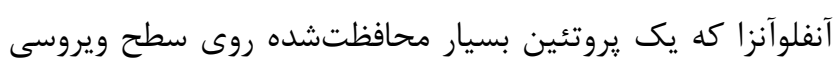

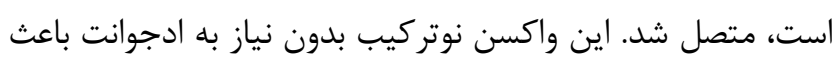

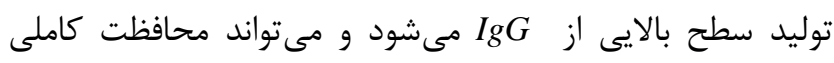
عليه آنفلوآنزاى كشنده موجب محافظت عليه دو سوية آنفلوآنزا HIN1 و و

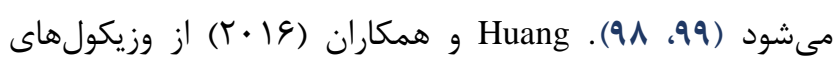

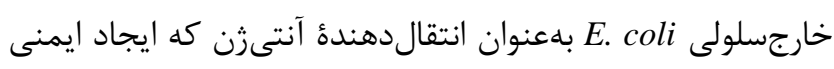

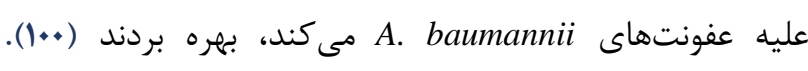
و Hasrris

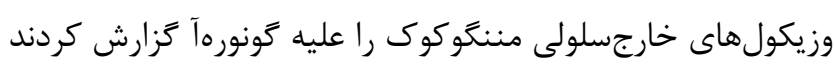

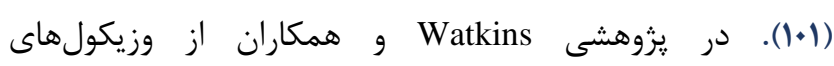
خارجسلولى نوتر كيب E. coli براى ايمنى عليه آنفلوآنزا بهره كرفته

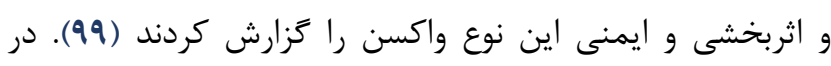

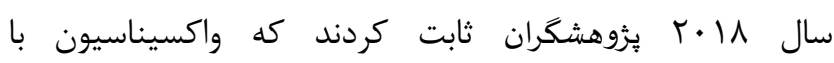

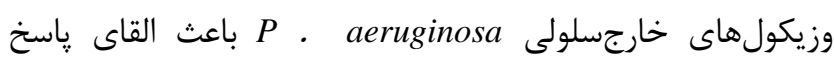
ايمنى در موش مىشود (r. (1). توانايى اين وزيكولها در فعالكردن سيستم ايمنى ذاتى،

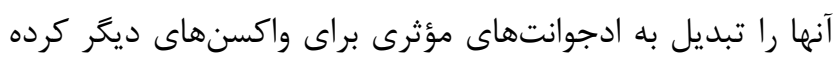

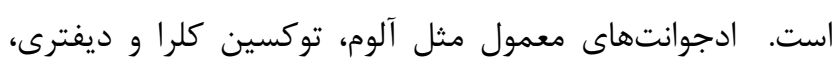

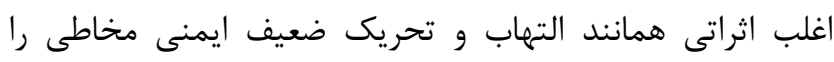

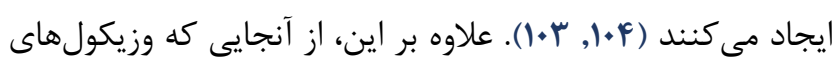

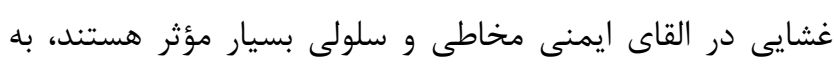

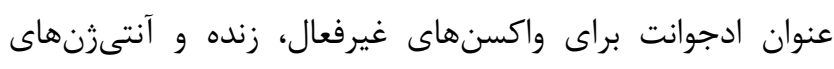

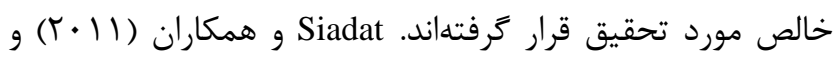
N. و همكاران (Y. Salmani meningitidis

\section{وزيكولهاى خارجسلولى بهعنوان سيستم تحويل

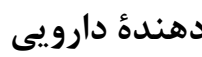

استفاده از وزيكولهاى خارجسلولى باكترىها بهناعنوان

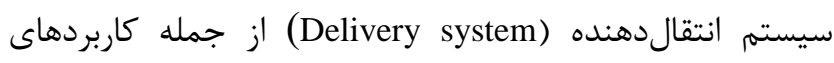

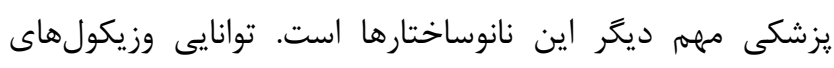

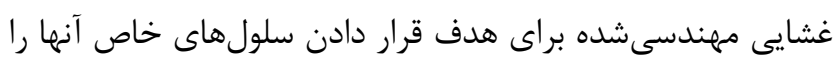




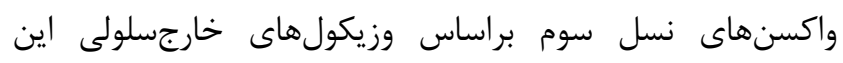

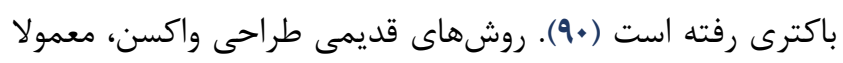

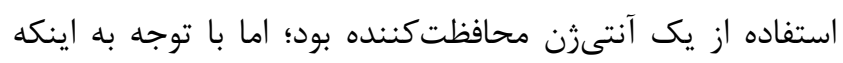

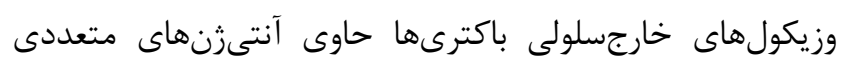

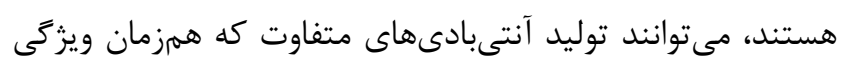

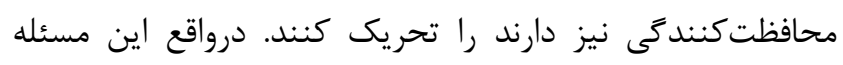

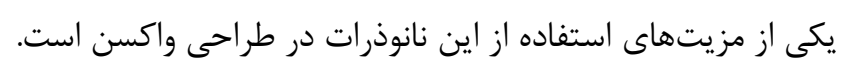

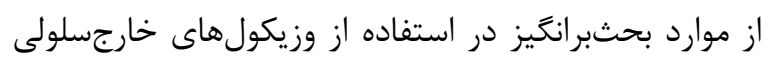

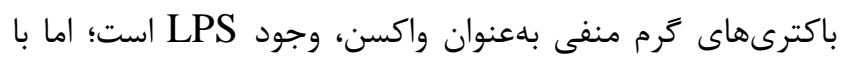

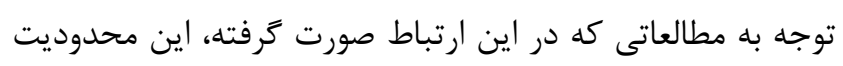

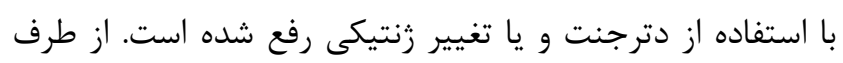

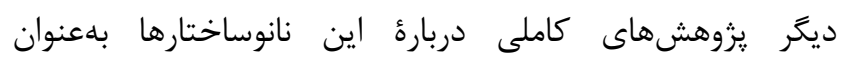
واكسنهاى غيرسلولى مؤثر براى استفاده كلينيكى در در انسان اندان

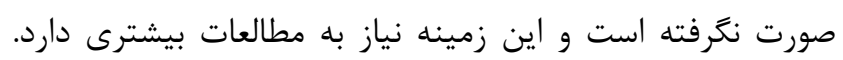

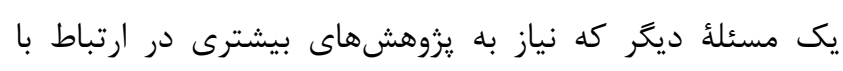

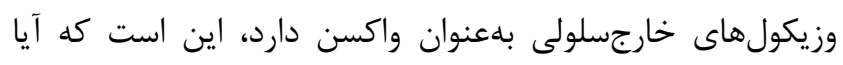

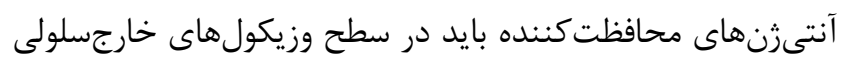

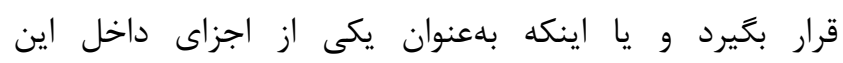
نانوساختارها باشد.

از مزيتهاى استفاده از وزيكولهاى خارجسلولى باكترىها

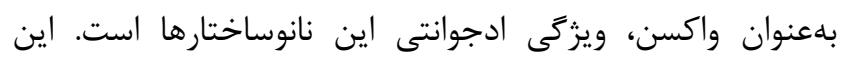

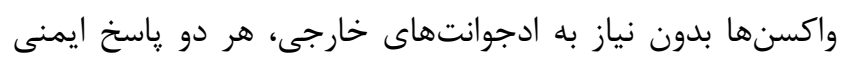

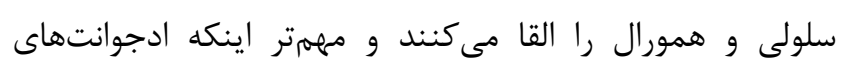
خارجى مثل آلوم كه تأييدشده براى استفاده روند روى انسان است،

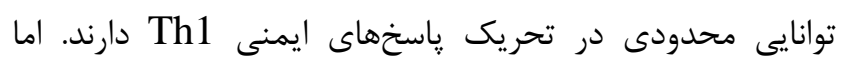

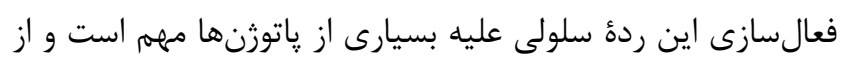

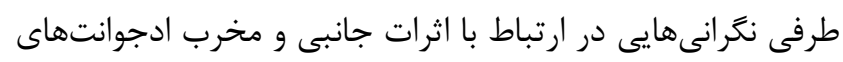

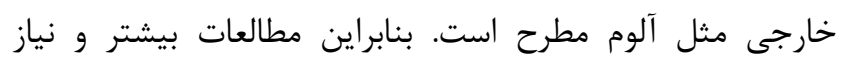
شديدترى به ادجوانتهاى مؤثر و ايمن براى الوم استفاده در انسان

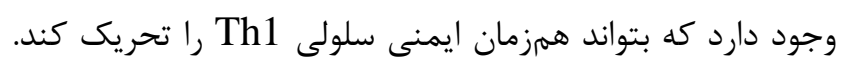

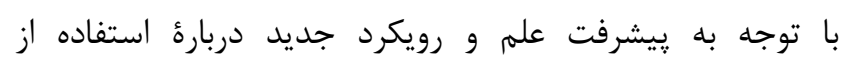

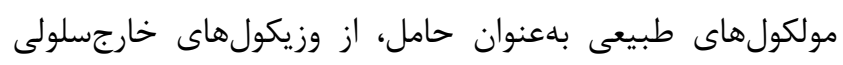

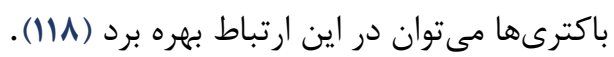

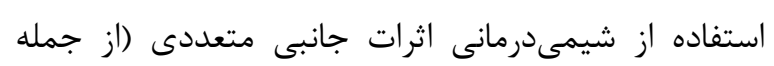

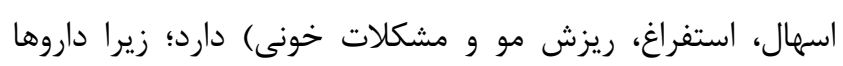

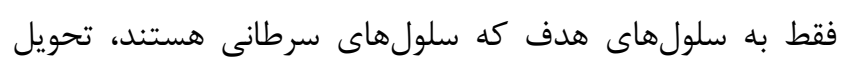

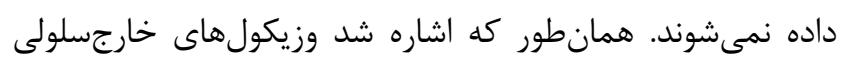

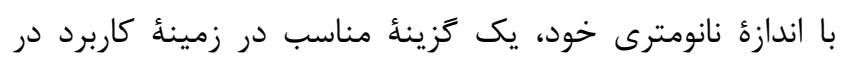

\section{توليد وزيكول هاى خارجسلولى نوتركيب}

سهولت نسبى تغيير باكترىها منجر به توسعهُ وزيكولهاى

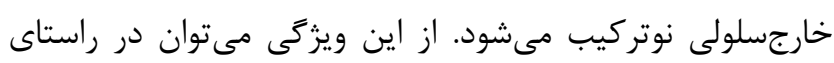

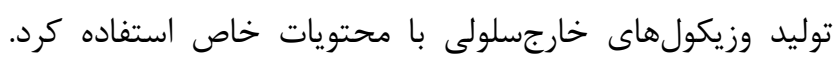

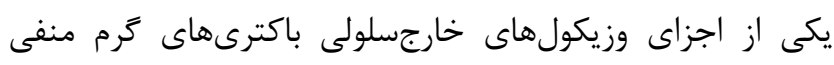

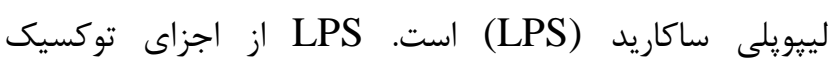
باكترىهاى كرم منفى محسوب مىشود كه مىتواند منجر بـ اليه

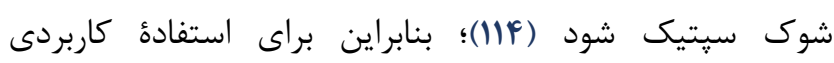

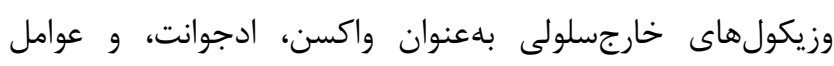

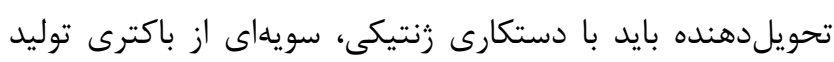

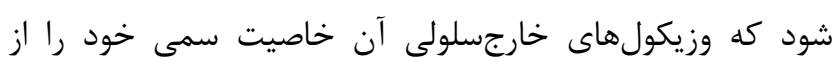

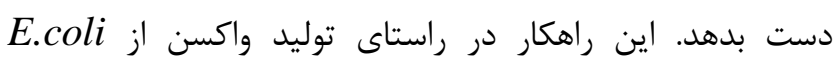

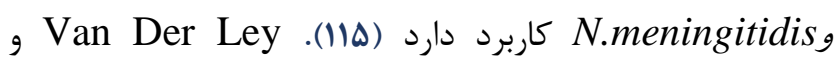

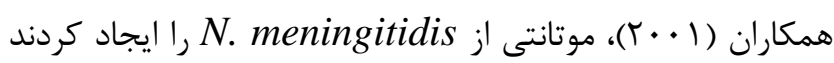

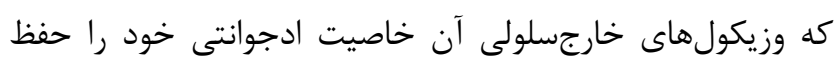

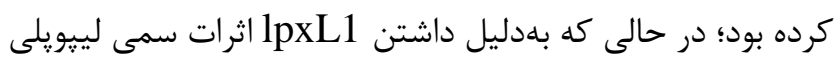

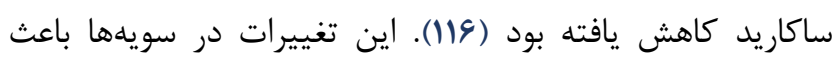

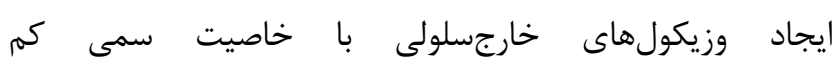

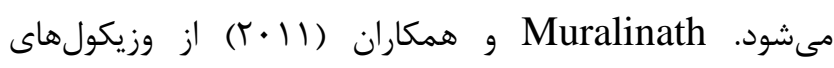
خارجسلولى Salmonella enterica مهندسى ونده براى بيان

يروتئين S.pneumoniae pspA استفاده كردند (ه) (9). امروزه وزيكولهاى خارجسلولى بهعنوان ابزار جديد درمانى لئن

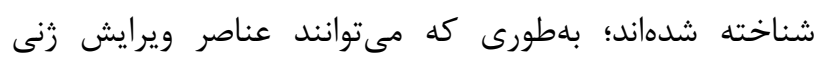
(CRISPR/Cassett)

\section{بحث و نتيجه كيرى}

وزيكولهاى خارجسلولى را انواعى از باكترىها ترشح

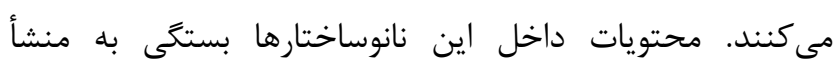

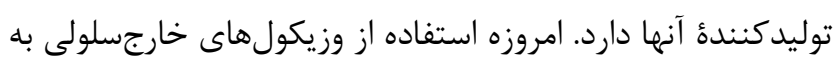

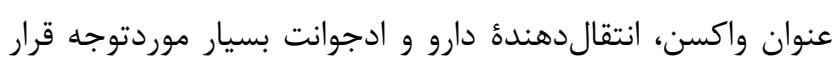

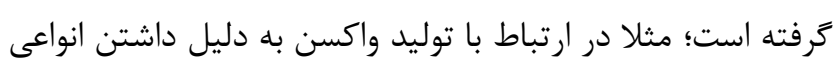

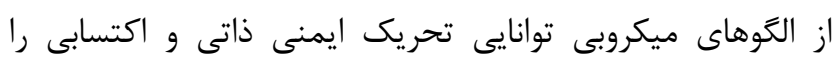

مطالعاتى كه در ارتباط با كاربرد وزيكولهاى خارجسلولى

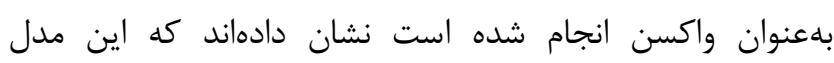

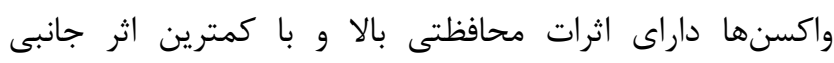

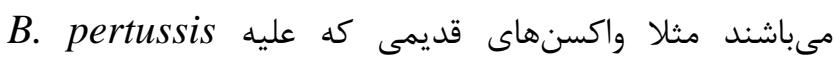

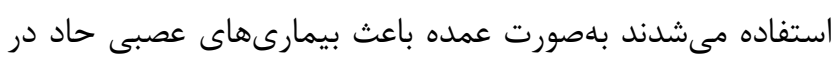

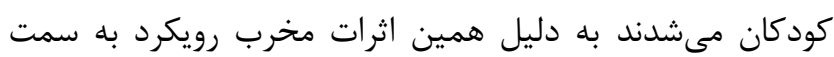


به شكل طبيعى از باكترى توليدكننده ترشح مىشوند، بسيار

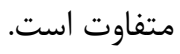
با توجه به يتانسيل وزيكولهاى خارجسلولى در انتقال

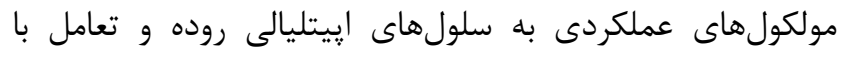

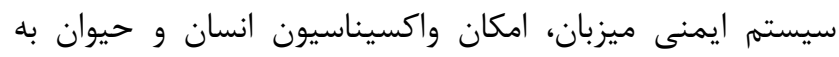

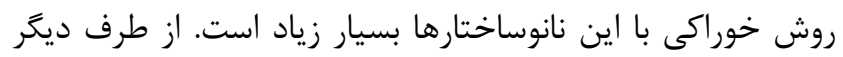

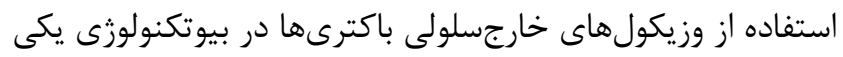
از موضوعات جالبتوجه است؛ به همين منظور از وزيكولهاى

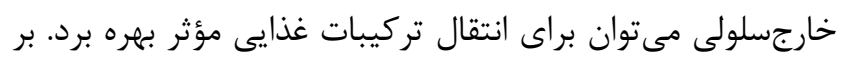
اين اساس وزيكولهاى خارجسلولى حاوى تركيبات مؤثر (انواعى از براز

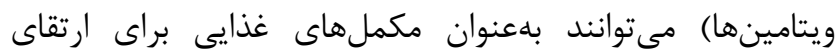
سلامتى مصرف شوند.

علاوه بر كاربرد وزيكولهاى خارجسلولى بلهنونوان واكسن،

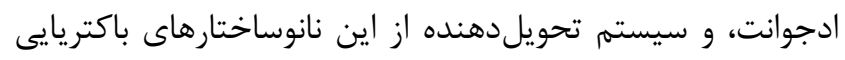

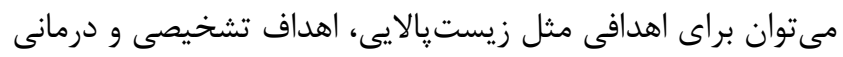

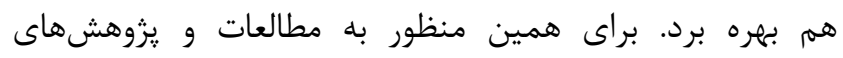
كَسترداى در ارتباط با اين نانوساختارها نياز است. سياسگزارى

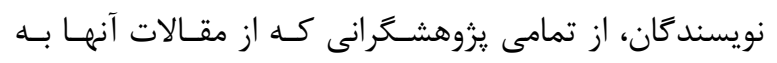
عنوان منابع استفاده شده است، تشكر و قدردانى مى كنند. بين نويسند تار منافع

\section{References}

1. Lee EY, Choi DY, Kim DK, Kim JW, Park $\mathrm{JO}$, Kim S, et al. Gram-positive bacteria produce membrane vesicles: proteomics-based characterization of Staphylococcus aureus-derived membrane vesicles. Proteomics. 2009;9(24):5425-36. https://doi.org/10.1002/pmic.200900338 PMID: 19834908

2. Soler N, Marguet E, Verbavatz J-M, Forterre P. Virus-like vesicles and extracellular DNA produced by hyperthermophilic archaea of the order Thermococcales. Res Microbiol. 2008;159(5):390-9. https://doi.org/10.1016/j.resmic.2008.04.015 PMID: 18625304
سيستمهاى هدفمند تحويل دارويى هستند. درواقع ما مىتوانيم با

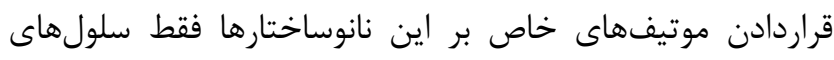

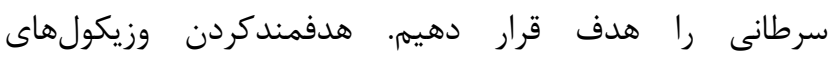
خارجسلولى بايد در حجم انبوه و به شكل خالص صورت بذئيرد كه

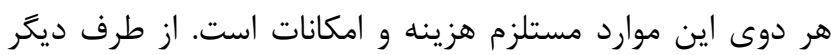

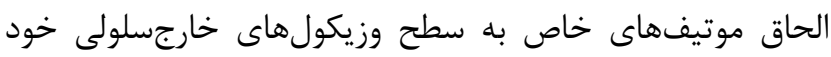

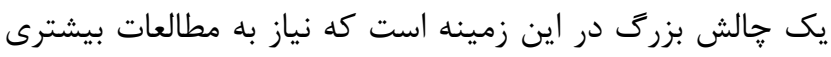

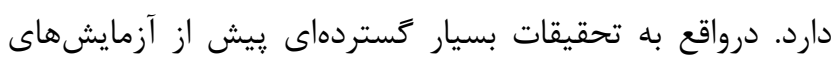

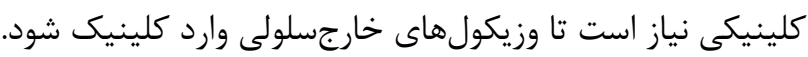

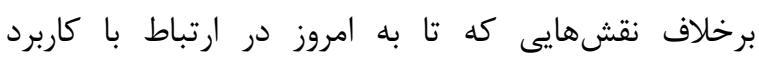

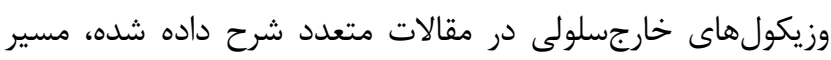

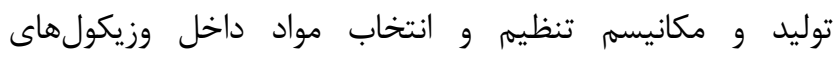
خارجسلولى و اينكه جه عواملى در توليد و ترشح اين نانوساختارها

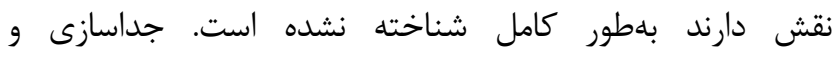
خالصسازى موفق و توليد مناسبى از اين نانوساختارها و ديكر اينكه

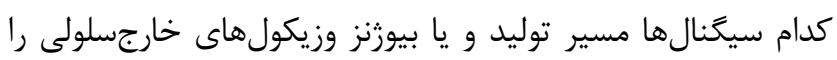

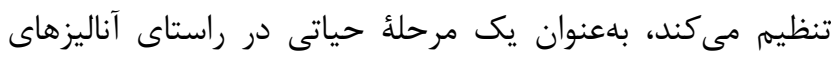
بعدى است. از طرف ديكر افزايش توليد وزيكول بهوسيلة بنأ تغييرات

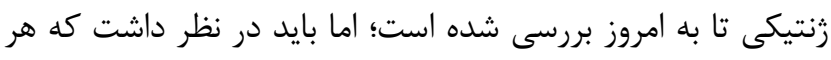

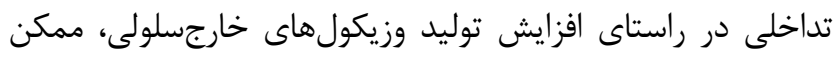

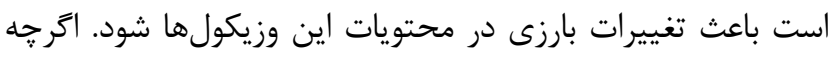

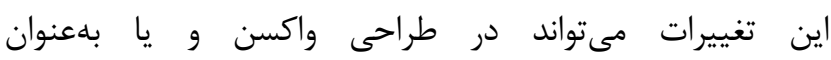

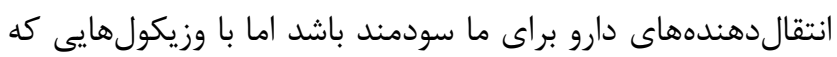

3. Lee EY, Choi DS, Kim KP, Gho YS. Proteomics in gram-negative bacterial outer membrane vesicles. Mass Spectrom Rev. 2008;27(6):535-55.

https://doi.org/10.1002/mas.20175

PMID: 18421767

4. Skog J, Wurdinger T, Van Rijn S, Meijer D, Gainche L, Sena-Esteves M, et al. Glioblastoma microvesicles transport RNA and protein that promote tumor growth and provide diagnostic biomarkers. Nat Cell Biol. 2008;10(12):1470-6.

https://doi.org/10.1038/ncb1800

PMID:19011622 PMCID:PMC3423894

5. Choi DS, Kim DK, Kim YK, Gho YS. Proteomics of extracellular vesicles: exosomes and ectosomes. Mass Spectrom 


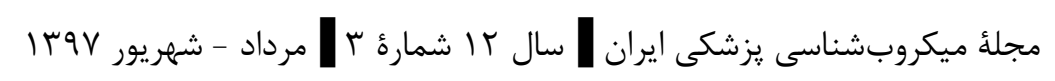

Rev.

2015;34(4):474-90.

https://doi.org/10.1002/mas.21420

PMID: 24421117

6. Kim D-K, Kang B, Kim OY, Choi D-s, Lee J, Kim SR, et al. EVpedia: an integrated database of high-throughput data for systemic analyses of extracellular vesicles. J Extracell Vesicles. 2013;2(1):20384. https://doi.org/10.3402/jev.v2i0.20384 PMID:24009897 PMCID:PMC3760654

7. Kulp A, Kuehn MJ. Biological functions and biogenesis of secreted bacterial outer membrane vesicles. Annu Rev Microbiol. 2010;64:163-84.

https://doi.org/10.1146/annurev.micro.09120 $\underline{8.073413}$ PMID:20825345

PMCID:PMC3525469

8. Lee EY, Bang JY, Park GW, Choi DS, Kang JS, Kim HJ, et al. Global proteomic profiling of native outer membrane vesicles derived from Escherichia coli. Proteomics. 2007;7(17):3143-53.

https://doi.org/10.1002/pmic.200700196 PMID: 17787032

9. Choi DS, Kim DK, Choi SJ, Lee J, Choi JP, Rho S, et al. Proteomic analysis of outer membrane vesicles derived from Pseudomonas aeruginosa. Proteomics. 2011;11(16):3424-9.

https://doi.org/10.1002/pmic.201000212 PMID:21751344

10. Post DM, Zhang D, Eastvold JS, Teghanemt A, Gibson BW, Weiss JP. Biochemical and functional characterization of membrane blebs purified from Neisseria meningitidis serogroup B. J Biol Chem. 2005;280(46):38383-94. https://doi.org/10.1074/jbc.M508063200 PMID:16103114

11. Wai SN, Lindmark B, Söderblom T, Takade A, Westermark M, Oscarsson $\mathrm{J}$, et al. Vesicle-mediated export and assembly of pore-forming oligomers of the enterobacterial ClyA cytotoxin. Cell. 2003;115(1):25-35. https://doi.org/10.1016/S0092$\underline{\text { 8674(03)00754-2 }}$
12. Kwon S-O, Gho YS, Lee JC, Kim SI. Proteome analysis of outer membrane vesicles from a clinical Acinetobacter baumannii isolate. FEMS Microbiol Lett. 2009;297(2):150-6.

https://doi.org/10.1111/j.15746968.2009.01669.x PMID:19548894

13. Schooling SR, Beveridge TJ. Membrane vesicles: an overlooked component of the matrices of biofilms. J Bacteriol. 2006;188(16):5945-57.

https://doi.org/10.1128/JB.00257-06

PMID:16885463 PMCID:PMC1540058

14. Toyofuku M, Roschitzki B, Riedel K, Eberl L. Identification of proteins associated with the Pseudomonas aeruginosa biofilm extracellular matrix. J Proteome Res. 2012;11(10):4906-15.

https://doi.org/10.1021/pr300395j

PMID:22909304

15. Yonezawa H, Osaki T, Kurata S, Fukuda M, Kawakami H, Ochiai K, et al. Outer membrane vesicles of Helicobacter pylori TK1402 are involved in biofilm formation. BMC Microbiol. 2009;9(1):197. https://doi.org/10.1186/1471-2180-9-197 PMID:19751530 PMCID:PMC2749055

16. Namork E, Brandtzaeg P. Fatal meningococcal septicaemia with "blebbing" meningococcus. Lancet.

2002;360(9347):1741.https://doi.org/10.1016 /S0140-6736(02)11721-1 PMID:12480427

17. Ünal CM, Schaar V, Riesbeck K, editors. Bacterial outer membrane vesicles in disease and preventive medicine. Seminars in immunopathology. New York: Springer; 2011.

18. Kuehn MJ, Kesty NC. Bacterial outer membrane vesicles and the host-pathogen interaction. Genes Dev. 2005;19(22):264555.https://doi.org/10.1101/gad.1299905 PMID: 16291643

19. Kulkarni HM, Jagannadham MV. Biogenesis and multifaceted roles of outer membrane vesicles from Gram-negative bacteria. Microbiology. 2014;160(10):2109-21. 
https://doi.org/10.1099/mic.0.079400-0

PMID:25069453

20. Dorward DW, Garon CF. DNA is packaged within membrane-derived vesicles of gramnegative but not gram-positive bacteria. Appl Environ Microbiol. 1990;56(6):1960-2. PMID:16348232 PMCID:PMC184538

21. Schwechheimer C, Kuehn MJ. Outermembrane vesicles from Gram-negative bacteria: biogenesis and functions. Nat Rev Microbiol. 2015;13(10):605-19. https://doi.org/10.1038/nrmicro3525 PMID:26373371 PMCID:PMC5308417

22. Kuehn MJ. Secreted bacterial vesicles as good Samaritans. Cell Host Microbe. 2012;12(4):392-3.

https://doi.org/10.1016/j.chom.2012.10.005 PMID:23084908

23. Mashburn LM, Whiteley M. Membrane vesicles traffic signals and facilitate group activities in a prokaryote. Nature. 2005;437(7057):422-5.

https://doi.org/10.1038/nature03925

PMID: 16163359

24. Renelli M, Matias V, Lo RY, Beveridge TJ. DNA-containing membrane vesicles of Pseudomonas aeruginosa PAO1 and their genetic transformation potential. Microbiology. 2004;150(7):2161-9. https://doi.org/10.1099/mic.0.26841-0 PMID: 15256559

25. Kolling GL, Matthews KR. Export of virulence genes and Shiga toxin by membrane vesicles of Escherichia coli O157: H7. Appl Environ Microbiol.1999; 65(5):1843-8. PMID: 10223967

26. Arigita $\mathrm{C}$, Jiskoot $\mathrm{W}$, Westdijk J, van Ingen C, Hennink WE, Crommelin DJ, et al. Stability of mono-and trivalent meningococcal outer membrane vesicle vaccines. Vaccine. 2004;22(5):629-42. https://doi.org/10.1016/j.vaccine.2003.08.027

27. Mashburn-Warren LM, Whiteley M. Special delivery: vesicle trafficking in prokaryotes. Mol Microbiol. 2006; 61(4):839-46. https://doi.org/10.1111/j.13652958.2006.05272.x PMID: 16879642

28. Ellis TN, Kuehn MJ. Virulence and immunomodulatory roles of bacterial outer membrane vesicles. Microbiol Mol Biol Rev. 2010;74(1):81-94.

https://doi.org/10.1128/MMBR.00031-09

PMID:20197500 PMCID:PMC2832350

29. MacDonald IA, Kuehn MJ. Offense and defense: microbial membrane vesicles play both ways. Res Microbiol. 2012;163(9):60718.https://doi.org/10.1016/j.resmic.2012.10.0 20 PMID:23123555

30. Vasilyeva NV, Tsfasman IM, Suzina NE, Stepnaya OA, Kulaev IS. Secretion of bacteriolytic endopeptidase L5 of Lysobacter sp. XL1 into the medium by means of outer membrane vesicles. The FEBS J. 2008;275(15):3827-35.

https://doi.org/10.1111/j.17424658.2008.065 30.x PMID: 18573103

31. Ciofu O, Beveridge TJ, Kadurugamuwa J, Walther-Rasmussen J, Høiby N. Chromosomal $\beta$-lactamase is packaged into membrane vesicles and secreted from Pseudomonas aeruginosa. J Antimicrob Chemother. 2000; 45(1): 9-13. https://doi.org/10.1093/jac/45.1.9

PMID: 10629007

32. Thuan Tong $\mathrm{T}$, Mörgelin M, Forsgren A, Riesbeck K. Haemophilus influenzae survival during complement-mediated attacks is promoted by Moraxella catarrhalis outer membrane vesicles. J Infect Dis. 2007;195(11):1661-70.

https://doi.org/10.1086/517611

PMID: 17471436

33. McBroom AJ, Kuehn MJ. Release of outer membrane vesicles by Gram-negative bacteria is a novel envelope stress response. Mol Microbiol. 2007;63(2):545-58.

https://doi.org/10.1111/j.13652958.2006.05522.x PMID: 17163978

34. Bomberger JM, MacEachran DP, Coutermarsh BA, Ye S, O'Toole GA, Stanton 


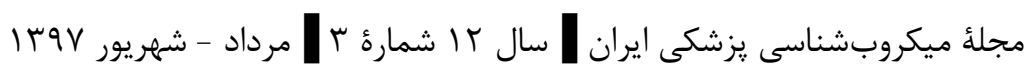

BA. Long-distance delivery of bacterial virulence factors by Pseudomonas aeruginosa outer membrane vesicles. PLoS Pathog. 2009;5(4):e1000382.

https://doi.org/10.1371/journal.ppat.1000382

PMID:19360133 PMCID:PMC2661024

35. Furuta N, Tsuda K, Omori H, Yoshimori T, Yoshimura F, Amano A. Porphyromonas gingivalis outer membrane vesicles enter human epithelial cells via an endocytic pathway and are sorted to lysosomal compartments. Infect Immun. 2009;77(10):4187-96.

https://doi.org/10.1128/IAI.00009-09 PMID:19651865 PMCID:PMC2747946

36. Kaparakis M, Turnbull L, Carneiro L, Firth $\mathrm{S}$, Coleman HA, Parkington $\mathrm{HC}$, et al. Bacterial membrane vesicles deliver peptidoglycan to NOD1 in epithelial cells. Cell Microbiol. 2010;12(3):372-85. https://doi.org/10.1111/j.14625822.2009.01404.x PMID:19888989

37. Ismail S, Hampton MB, Keenan JI. Helicobacter pylori outer membrane vesicles modulate proliferation and interleukin-8 production by gastric epithelial cells. Infect Immun. 2003;71(10):5670-5.

https://doi.org/10.1128/IAI.71.10.56705675.2003 PMID:14500487

38. Elmi A, Watson E, Sandu P, Gundogdu O, Mills DC, Inglis NF, et al. Campylobacter jejuni outer membrane vesicles play an important role in bacterial interactions with human intestinal epithelial cells. Infect Immun. 2012;80(12):4089-98. https://doi.org/10.1128/IAI.00161-12 PMID:22966047 PMCID:PMC3497446

39. Rolhion N, Barnich N, Bringer M-A, Glasser A-L, Ranc J, Hébuterne X, et al. Abnormally expressed ER stress response chaperone Gp96 in CD favours adherent-invasive Escherichia coli invasion. Gut. 2010;59(10):1355-62. https://doi.org/10.1136/gut.2010.207456 PMID:20587550 PMCID:PMC2976078
40. Kunsmann L, Rüter C, Bauwens A, Greune L, Glüder M, Kemper B, et al. Virulence from vesicles: Novel mechanisms of host cell injury by Escherichia coli O104: H4 outbreak strain. Sci Rep. 2015;5:13252. https://doi.org/10.1038/srep13252

41. Mondal A, Tapader R, Chatterjee NS, Ghosh A, Sinha R, Koley H, et al. Cytotoxic and inflammatory responses induced by outer membrane vesicle-associated biologically active proteases from Vibrio cholerae. Infect Immun. 2016;84(5):1478-90. https://doi.org/10.1128/IAI.01365-15 PMID:26930702 PMCID:PMC4862697

42. Li Z-T, Zhang R-L, Bi X-G, Xu L, Fan M, Xie $\mathrm{D}$, et al. Outer membrane vesicles isolated from two clinical Acinetobacter baumannii strains exhibit different toxicity and proteome characteristics. Microb Pathog. 2015;81:46-52.

https://doi.org/10.1016/j.micpath.2015.03.00 $\underline{9}$ PMID:25773772

43. Alzahrani H, Winter J, Boocock D, De Girolamo L, Forsythe SJ. Characterization of outer membrane vesicles from a neonatal meningitic strain of Cronobacter sakazakii. FEMS Microbiol Lett. 2015;362(12):fnv085. https://doi.org/10.1093/femsle/fnv085 PMID:26023200

44. Ghosal A, Upadhyaya BB, Fritz JV, Heintz-Buschart A, Desai MS, Yusuf D, et al. The extracellular RNA complement of Escherichia coli. Microbiologyopen. 2015;4(2):252-66. https://doi.org/10.1002/mbo3.235 PMID:25611733 PMCID:PMC4398507

45. Koeppen K, Hampton TH, Jarek M, Scharfe M, Gerber SA, Mielcarz DW, et al. A novel mechanism of host-pathogen interaction through sRNA in bacterial outer membrane vesicles. PLoS Pathog. 2016;12(6):e1005672. https://doi.org/10.1371/journal.ppat.1005672 PMID:27295279 PMCID:PMC4905634

46. Ho M-H, Chen C-H, Goodwin JS, Wang B$\mathrm{Y}$, Xie $\mathrm{H}$. Functional advantages of Porphyromonas gingivalis vesicles. PloS one. 
2015;10(4):e0123448.

https://doi.org/10.1371/journal.pone.0123448

PMID:25897780 PMCID:PMC4405273

47. Sjöström AE, Sandblad L, Uhlin BE, Wai $\mathrm{SN}$. Membrane vesicle-mediated release of bacterial RNA. Sci Rep. 2015;5:15329. https://doi.org/10.1038/srep15329

PMID:26483327 PMCID:PMC4612299

48. Aung KM, Sjöström AE, von PawelRammingen U, Riesbeck K, Uhlin BE, Wai SN. Naturally occurring IgG antibodies provide innate protection against Vibrio cholerae bacteremia by recognition of the outer membrane protein U. J Innate Immun. 2016;8(3):269-83.

https://doi.org/10.1159/000443646

PMID:26934383

49. Bielecka E, Scavenius C, Kantyka T, Jusko M, Mizgalska D, Szmigielski B, et al. Peptidyl arginine deiminase from Porphyromonas gingivalis abolishes anaphylatoxin C5a activity. J Biol Chem. 2014;289(47):32481-7.

https://doi.org/10.1074/jbc.C114.617142

PMID:25324545 PMCID:PMC4239603

50. Bottazzi B, Santini L, Savino S, Giuliani MM, Díez AID, Mancuso G, et al. Recognition of Neisseria meningitidis by the long pentraxin PTX3 and its role as an endogenous adjuvant. PloS one. 2015;10(3):e0120807.

https://doi.org/10.1371/journal.pone.0120807 PMID:25786110 PMCID:PMC4364741

51. Laughlin RC, Mickum M, Rowin K, Adams LG, Alaniz RC. Altered host immune responses to membrane vesicles from Salmonella and Gram-negative pathogens. Vaccine. 2015;33(38):5012-9.

https://doi.org/10.1016/j.vaccine.2015.05.014 PMID:26001432

52. Waller T, Kesper L, Hirschfeld J, Dommisch H, Kölpin J, Oldenburg J, et al. Porphyromonas gingivalis outer membrane vesicles induce selective tumor necrosis factor tolerance in a toll-like receptor 4 -and
mTOR-dependent manner. Infection and immunity. 2016;84(4):1194-204. https://doi.org/10.1128/IAI.01390-15 PMID:26857578 PMCID:PMC4807478

53. Shen Y, Torchia MLG, Lawson GW, Karp CL, Ashwell JD, Mazmanian SK. Outer membrane vesicles of a human commensal mediate immune regulation and disease protection. Cell host \& microbe. 2012;12(4):509-20.

https://doi.org/10.1016/j.chom.2012.08.004 PMID:22999859 PMCID:PMC3895402

54. Lee HS, Boulton IC, Reddin K, Wong H, Halliwell D, Mandelboim O, et al. Neisserial outer membrane vesicles bind the coinhibitory receptor carcinoembryonic antigen-related cellular adhesion molecule 1 and suppress CD4+ T lymphocyte function. Infect Immun. 2007;75(9):4449-55.

https://doi.org/10.1128/IAI.00222-07 PMID:17620353 PMCID:PMC1951172

55. Jones C, Sadarangani M, Lewis S, Payne I, Saleem M, Derrick JP, et al. Characterisation of the immunomodulatory effects of meningococcal Opa proteins on human peripheral blood mononuclear cells and CD4+ $\mathrm{T}$ cells. PloS one. 2016;11(4):e0154153.

https://doi.org/10.1371/journal.pone.0154153

\section{PMID:27111850 PMCID:PMC4844130}

56. Winter J, Letley D, Rhead J, Atherton J, Robinson K. Helicobacter pylori membrane vesicles stimulate innate pro-and antiinflammatory responses and induce apoptosis in Jurkat $\mathrm{T}$ cells. Infect Immun. 2014;82(4):1372-81.

https://doi.org/10.1128/IAI.01443-13 PMID:24421041 PMCID:PMC3993389

57. Deknuydt F, Nordström $T$, Riesbeck K. Diversion of the host humoral response: a novel virulence mechanism of Haemophilus influenzae mediated via outer membrane vesicles. J Leukoc Biol. 2014;95(6):983-91. https://doi.org/10.1189/jlb.1013527 PMID:24550522 


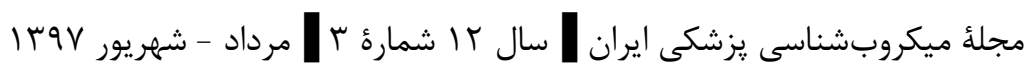

58. Kim JH, Lee J, Park J, Gho YS, editors. Gram-negative and Gram-positive bacterial extracellular vesicles. Seminars in cell \& developmental biology. New York: Elsevier; 2015.

59. Rivera J, Cordero RJ, Nakouzi AS, Frases S, Nicola A, Casadevall A. Bacillus anthracis produces membrane-derived vesicles containing biologically active toxins. Proceedings of the National Academy of Sciences. 2010;107(44):19002-7. https://doi.org/10.1073/pnas.1008843107 PMID:20956325 PMCID:PMC2973860

60. Olaya-Abril A, Prados-Rosales R, McConnell MJ, Martín-Pe-a R, GonzálezReyes JA, Jiménez-Munguía I, et al. Characterization of protective extracellular membrane-derived vesicles produced by Streptococcus pneumoniae. J Proteomics. 2014;106:46-60. https://doi.org/10.1016/j.jprot.2014.04.023 PMID:24769240

61. Hong SW, Kim MR, Lee EY, Kim J, Kim YS, Jeon S, et al. Extracellular vesicles derived from staphylococcus aureus induce atopic dermatitis-like skin inflammation. Allergy. 2011;66(3):351-9.

https://doi.org/10.1111/j.13989995.2010.02483.x $\quad$ PMID:20831718 PMCID:PMC3052535

62. Hong SW, Choi E-B, Min T-K, Kim J-H, Kim M-H, Jeon SG, et al. An important role of $\alpha$-hemolysin in extracellular vesicles on the development of atopic dermatitis induced by Staphylococcus aureus. PLoS One. 2014;9(7):e100499.

https://doi.org/10.1371/journal.pone.0100499 PMID:24992681 PMCID:PMC4084635

63. Kim MR, Hong SW, Choi EB, Lee WH, Kim YS, Jeon S, et al. Staphylococcus aureus-derived extracellular vesicles induce neutrophilic pulmonary inflammation via both Th1 and Th17 cell responses. Allergy. 2012;67(10):1271-81. https://doi.org/10.1111/all.12001

PMID:22913540
64. Lee J, Lee E-Y, Kim S-H, Kim D-K, Park K$\mathrm{S}$, Kim KP, et al. Staphylococcus aureus extracellular vesicles carry biologically active $\beta$-lactamase. Antimicrob Agents Chemother. 2013;57(6):2589-95.

https://doi.org/10.1128/AAC.00522-12 PMID:23529736 PMCID:PMC3716153

65. Gurung M, Moon DC, Choi CW, Lee JH, Bae YC, Kim J, et al. Staphylococcus aureus produces membrane-derived vesicles that induce host cell death. PLoS one. 2011;6(11):e27958.

https://doi.org/10.1371/journal.pone.0027958 PMID:22114730 PMCID:PMC3218073

66. George KM, Chatterjee D, Gunawardana G, Welty D, Hayman J, Lee R, et al. Mycolactone: a polyketide toxin from Mycobacterium ulcerans required for virulence. Science. 1999;283(5403):854-7.

https://doi.org/10.1126/science.283.5403.854 PMID: 9933171

67. Marsollier L, Brodin $\mathrm{P}$, Jackson $\mathrm{M}$, Korduláková J, Tafelmeyer P, Carbonnelle E, et al. Impact of Mycobacterium ulcerans biofilm on transmissibility to ecological niches and Buruli ulcer pathogenesis. PLoS Pathog. 2007;3(5):e62. https://doi.org/10.1371/journal.ppat.0030062 PMID:17480118 PMCID:PMC1864991

68. Prados-Rosales R, Baena A, Martinez LR, Luque-Garcia J, Kalscheuer R, Veeraraghavan U, et al. Mycobacteria release active membrane vesicles that modulate immune responses in a TLR2-dependent manner in mice. $\mathrm{J}$ Clin Invest. 2011;121(4):1471-83.

https://doi.org/10.1172/JCI44261 PMID:21364279 PMCID:PMC3069770

69. Lee JH, Choi C-W, Lee T, Kim SI, Lee J-C, Shin J-H. Transcription factor $\sigma \mathrm{B}$ plays an important role in the production of extracellular membrane-derived vesicles in Listeria monocytogenes. PLoS one. 2013;8(8):e73196. https://doi.org/10.1371/journal.pone.0073196 PMID:23977379 PMCID:PMC3748028 
70. Makarova K, Slesarev A, Wolf Y, Sorokin A, Mirkin B, Koonin E, et al. Comparative genomics of the lactic acid bacteria. Proc Natl Acad Sci U S A. 2006;103(42):15611-6. https://doi.org/10.1073/pnas.0607117103 PMID:17030793 PMCID:PMC1622870

71. Dobrogosz WJ, Peacock TJ, Hassan HM. Evolution of the probiotic concept: from conception to validation and acceptance in medical science. Adv Appl Microbiol. 2010;72:1-41.

https://doi.org/10.1016/S00652164(10)72001-3 PMID:20602986

72. Kim Y-G, Ohta T, Takahashi T, Kushiro A, Nomoto K, Yokokura T, et al. Probiotic Lactobacillus casei activates innate immunity via NF- $\kappa \mathrm{B}$ and p38 MAP kinase signaling pathways. Microbes Infect. 2006;8(4):9941005.https://doi.org/10.1016/j.micinf.2005.1 $\underline{0.019}$ PMID: $\underline{16513392}$

73. Yan F, Polk DB. Probiotic bacterium prevents cytokine-induced apoptosis in intestinal epithelial cells. J Biol Chem. 2002;277(52):50959-65.

https://doi.org/10.1074/jbc.M207050200

PMID:12393915 PMCID:PMC4006994

74. Medellin-Pena MJ, Griffiths MW. Effect of molecules secreted by Lactobacillus acidophilus strain La-5 on Escherichia coli O157: H7 colonization. Appl Environ Microbiol. 2009;75(4):1165-72. https://doi.org/10.1128/AEM.01651-08 PMID:19088323 PMCID:PMC2643578

75. Manley KJ, Fraenkel MB, Mayall BC, Power DA. Probiotic treatment of vancomycinresistant enterococci: a randomised controlled trial. Med J Aust. 2007;186(9):454-6.

PMID: 17484706

76. Castillo NA, Perdigón G, de LeBlanc AdM. Oral administration of a probiotic Lactobacillus modulates cytokine production and TLR expression improving the immune response against Salmonella enterica serovar Typhimurium infection in mice. BMC
Microbiol. 2011;11(1):177.

https://doi.org/10.1186/1471-2180-11-177

PMID:21813005 PMCID:PMC3173335

77. Walker WA. Mechanisms of action of probiotics. Clin Infect Dis. 2008;46(S2):S8791. $\quad$ https://doi.org/10.1086/523335 PMID: $\underline{18181730}$

78. Ng S, Hart A, Kamm M, Stagg A, Knight S. Mechanisms of action of probiotics: recent advances. Inflamm Bowel Dis. 2009;15(2):300-10.

https://doi.org/10.1002/ibd.20602

PMID: 18626975

79. Todorov SD. Bacteriocins from Lactobacillus plantarum production, genetic organization and mode of action: produção, organização genética e modo de ação. Braz J Microbiol. 2009;40(2):209-21.

https://doi.org/10.1590/S1517-

$\begin{array}{ll}\text { 83822009000200001 } & \text { PMID:24031346 } \\ \text { PMCID:PMC3769724 }\end{array}$

80. Corthésy B, Gaskins HR, Mercenier A. Cross-talk between probiotic bacteria and the host immune system. J Nutr. 2007;137(3):781S-90S. https://doi.org/10.1093/jn/137.3.781S PMID: 17311975

81. Ruiz L, Hevia A, Bernardo D, Margolles A, Sánchez B. Extracellular molecular effectors mediating probiotic attributes. FEMS Microbiol Lett. 2014;359(1):1-11. https://doi.org/10.1111/1574-6968.12576 PMID:25115731

82. van Bergenhenegouwen J, Kraneveld AD, Rutten L, Kettelarij N, Garssen J, Vos AP. Extracellular vesicles modulate host-microbe responses by altering TLR2 activity and phagocytosis. PLoS One. 2014 Feb 20;9(2):e89121.

83. Li M, Lee K, Hsu M, Nau G, Mylonakis E, Ramratnam B. Lactobacillus-derived extracellular vesicles enhance host immune responses against vancomycin-resistant enterococci. BMC Microbiol. 2017;17(1):66. https://doi.org/10.1186/s12866-017-0977-7 PMID:28288575 PMCID:PMC5348868 
84. Kim J-H, Jeun E-J, Hong C-P, Kim S-H, Jang MS, Lee E-J, et al. Extracellular vesicle-derived protein from Bifidobacterium longum alleviates food allergy through mast cell suppression. Journal of Allergy and Clinical Immunology. 2016;137(2):507-16. e8.

85. Brown L, Wolf JM, Prados-Rosales R, Casadevall A. Through the wall: extracellular vesicles in Gram-positive bacteria, mycobacteria and fungi. Nat Rev Microbiol. 2015;13(10):620-30.

86. Twu O, de Miguel N, Lustig G, Stevens GC, Vashisht AA, Wohlschlegel JA, et al. Trichomonas vaginalis exosomes deliver cargo to host cells and mediate host: parasite interactions. PLoS pathogens. 2013;9(7):e1003482.

87. Szempruch AJ, Sykes SE, Kieft R, Dennison L, Becker AC, Gartrell A, et al. Extracellular vesicles from Trypanosoma brucei mediate virulence factor transfer and cause host anemia. Cell. 2016;164(1):246-57. https://doi.org/10.1016/j.cell.2015.11.051 PMID:26771494 PMCid:PMC4715261

88. Mantel P-Y, Hoang AN, Goldowitz I, Potashnikova D, Hamza B, Vorobjev I, et al. Malaria-infected erythrocyte-derived microvesicles mediate cellular communication within the parasite population and with the host immune system. Cell Host Microbe. 2013;13(5):521-34. https://doi.org/10.1016/j.chom.2013.04.009 PMID:23684304 PMCID:PMC3687518

89. Regev-Rudzki N, Wilson DW, Carvalho TG, Sisquella X, Coleman BM, Rug M, et al. Cell-cell communication between malariainfected red blood cells via exosome-like vesicles. Cell. 2013;153(5):1120-33. https://doi.org/10.1016/j.cell.2013.04.029 PMID:23683579

90. Raeven RH, Brummelman J, Pennings JL, Van Der Maas L, Tilstra W, Helm K, et al. Bordetella pertussis outer membrane vesicle vaccine confers equal efficacy in mice with milder inflammatory responses compared to a whole-cell vaccine. Sci Rep. 2016;6:38240. https://doi.org/10.1038/srep38240

PMID:27905535 PMCID:PMC5131296

91. Raeven RH, van der Maas L, Tilstra W, Uittenbogaard JP, Bindels TH, Kuipers B, et al. Immunoproteomic profiling of Bordetella pertussis outer membrane vesicle vaccine reveals broad and balanced humoral immunogenicity. J Proteome Res. 2015;14(7):2929-42.

https://doi.org/10.1021/acs.jproteome.5b0025 8 PMID:25988566

92. Zariri A, Beskers J, van de Waterbeemd B, Hamstra HJ, Bindels TH, van Riet E, et al. Meningococcal outer membrane vesicle composition-dependent activation of the innate immune response. Infect Immun. 2016;84(10):3024-33. https://doi.org/10.1128/IAI.00635-16

93. Choi SJ, Kim MH, Jeon J, Kim OY, Choi Y, Seo J, et al. Active immunization with extracellular vesicles derived from Staphylococcus aureus effectively protects against staphylococcal lung infections, mainly via Th1 cell-mediated immunity. PloS one. 2015;10(9):e0136021.

94. McConnell MJ, Rumbo C, Bou G, Pachón J. Outer membrane vesicles as an acellular vaccine against Acinetobacter baumannii. Vaccine. 2011;29(34):5705-10. https://doi.org/10.1016/j.vaccine.2011.06.001 PMID:21679737

95. Muralinath M, Kuehn MJ, Roland KL, Curtiss R. Immunization with Salmonella enterica serovar Typhimurium-derived outer membrane vesicles delivering the pneumococcal protein PspA confers protection against challenge with Streptococcus pneumoniae. Infect Immun. 2011;79(2):887-94.

https://doi.org/10.1128/IAI.00950-10 PMID:21115718 PMCID:PMC3028854

96. Schild S, Nelson EJ, Camilli A. Immunization with Vibrio cholerae outer membrane vesicles induces protective immunity in mice. Infect Immun. 2008;76(10):4554-63. 
https://doi.org/10.1128/IAI.00532-08

PMID:18678672 PMCID:PMC2546833

97. Nakao R, Senpuku $H$, Watanabe $H$. Porphyromonas gingivalis galE is involved in lipopolysaccharide $\mathrm{O}$-antigen synthesis and biofilm formation. Infect Immun. 2006;74(11):6145-53.

https://doi.org/10.1128/IAI.00261-06 PMID: 16954395 PMCID:PMC1695533

98. Rappazzo CG, Watkins HC, Guarino CM, Chau A, Lopez JL, DeLisa MP, et al. Recombinant M2e outer membrane vesicle vaccines protect against lethal influenza $A$ challenge in BALB/c mice. Vaccine. 2016;34(10):1252-8.

https://doi.org/10.1016/j.vaccine.2016.01.028 PMID:26827663

99. Watkins HC, Rappazzo CG, Higgins JS, Sun X, Brock N, Chau A, et al. Safe recombinant outer membrane vesicles that display M2e elicit heterologous influenza protection. Mol Ther. 2017;25(4):989-1002. https://doi.org/10.1016/j.ymthe.2017.01.010 PMID:28215994 PMCID:PMC5383554

100. Huang W, Wang S, Yao Y, Xia Y, Yang X, $\mathrm{Li} \mathrm{K}$, et al. Employing Escherichia coliderived outer membrane vesicles as an antigen delivery platform elicits protective immunity against Acinetobacter baumannii infection. Sci Rep. 2016;6:37242. https://doi.org/10.1038/srep37242

\section{PMID:27849050 PMCID:PMC5110958}

101. Petousis-Harris H, Paynter J, Morgan J, Saxton P, McArdle B, Goodyear-Smith F, et al. Effectiveness of a group $B$ outer membrane vesicle meningococcal vaccine against gonorrhoea in New Zealand: a retrospective case-control study. The Lancet. 2017;390(10102):1603-10.

102. Zhang X, Yang F, Zou J, Wu W, Jing H, Gou $\mathrm{Q}$, et al. Immunization with Pseudomonas aeruginosa outer membrane vesicles stimulates protective immunity in mice. Vaccine. 2018;36(8):1047-54.
103. Chapman TJ, Georas SN. Adjuvant effect of diphtheria toxin after mucosal administration in both wild type and diphtheria toxin receptor engineered mouse strains. $\mathbf{J}$ Immunol Methods. 2013;400:122-6. https://doi.org/10.1016/j.jim.2013.10.010 PMID:24200744 PMCID:PMC3873768

104. Petrovsky N, Aguilar JC. Vaccine adjuvants: current state and future trends. Immunol Cell Biol. 2004;82(5):488-96. https://doi.org/10.1111/j.08189641.2004.01272.x PMID:15479434

105. Siadat SD, Naddaf SR, Zangeneh M, Moshiri A, Sadat SM, Ardestani MS, et al. Outer membrane vesicle of Neisseria meningitidis serogroup B as an adjuvant in immunization of rabbit against Neisseria meningitidis serogroup A. Afr J Microbiol Res. 2011;5(19):3090-5. https://doi.org/10.5897/AJMR11.361

106. Salmani AS, Siadat SD, Norouzian D, Mobarakeh JI, Kheirandish M, Zangeneh M, et al. Outer membrane vesicle ofNeisseria meningitidis serogroup B as an adjuvant to induce specific antibody response against the lipopolysaccharide ofBrucella abortus S99. Annals of microbiology. 2009;59(1):145. https://doi.org/10.1007/BF03175612

107. Gujrati VB, Jon S. Bioengineered bacterial outer membrane vesicles: what is their potential in cancer therapy? Nanomedicine. 2014;9(7):933-5.

https://doi.org/10.2217/nnm.14.56 PMID:24978458

108. Kim OY, Park HT, Dinh NTH, Choi SJ, Lee $\mathrm{J}$, Kim JH, et al. Bacterial outer membrane vesicles suppress tumor by interferon- $\gamma$ mediated antitumor response. Nat Commun. 2017;8(1):626.

https://doi.org/10.1038/s41467-017-00729-8 PMID:28931823 PMCID:PMC5606984

109. Miller KD, Siegel RL, Lin CC, Mariotto AB, Kramer JL, Rowland JH, et al. Cancer treatment and survivorship statistics, 2016. CA Cancer J Clin. 2016;66(4):271-89. 


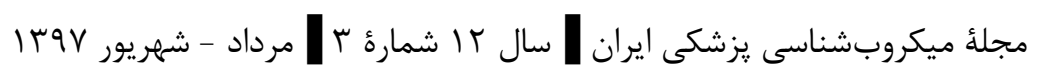

https://doi.org/10.3322/caac.21349

PMID:27253694

110. Iyer AK, Singh A, Ganta S, Amiji MM. Role of integrated cancer nanomedicine in overcoming drug resistance. Adv Drug Deliv Rev. 2013;65(13):1784-802. https://doi.org/10.1016/j.addr.2013.07.012 PMID:23880506

111. Gujrati V, Kim S, Kim S-H, Min JJ, Choy $\mathrm{HE}$, Kim SC, et al. Bioengineered bacterial outer membrane vesicles as cell-specific drug-delivery vehicles for cancer therapy. ACS Nano. 2014;8(2):1525-37. https://doi.org/10.1021/nn405724x

PMID:24410085

112. Kim OY, Dinh NTH, Park HT, Choi SJ, Hong K, Gho YS. Bacterial protoplastderived nanovesicles for tumor targeted delivery of chemotherapeutics. Biomaterials. 2017;113:68-79.

https://doi.org/10.1016/j.biomaterials.2016.1 $\underline{0.037}$ PMID:27810643

113. Alves NJ, Turner KB, Daniele MA, Oh E, Medintz IL, Walper SA. Bacterial nanobioreactors-directing enzyme packaging into bacterial outer membrane vesicles. ACS Appl Mater Interfaces. 2015;7(44):24963-72. https://doi.org/10.1021/acsami.5b08811 PMID: 26479678

114. Kim JH, Yoon YJ, Lee J, Choi E-J, Yi N, Park K-S, et al. Outer membrane vesicles derived from Escherichia coli up-regulate expression of endothelial cell adhesion molecules in vitro and in vivo. PLoS one. 2013;8(3):e59276.

https://doi.org/10.1371/journal.pone.0059276 PMID:23516621 PMCID:PMC3597602

115. Alves NJ, Turner KB, Medintz IL, Walper SA. Emerging therapeutic delivery capabilities and challenges utilizing enzyme/protein packaged bacterial vesicles. Ther Deliv. 2015;6(7):87387.https://doi.org/10.4155/tde. 15.40 PMID:26228777

116. Van Der Ley P, Steeghs L, Hamstra HJ, ten Hove J, Zomer B, van Alphen L.
Modification of Lipid A Biosynthesis inNeisseria meningitidis lpxL Mutants: Influence on Lipopolysaccharide Structure, Toxicity, and Adjuvant Activity. Infect Immun. 2001;69(10):5981-90. https://doi.org/10.1128/IAI.69.10.59815990.2001 PMID: 11553534

117. Wang L, Li F, Dang L, Liang C, Wang C, He $\mathrm{B}$, et al. In vivo delivery systems for therapeutic genome editing. Int $\mathrm{J}$ Mol Sci. 2016;17(5):626.

https://doi.org/10.3390/ijms17050626

PMID:27128905 PMCID:PMC4881452

118. Sheikhpour M, Barani L, Kasaeian A. Biomimetics in drug delivery systems: A critical review. J Control Release. 2017;253:97-109. https://doi.org/10.1016/j.jconrel.2017.03.026 PMID:28322976 